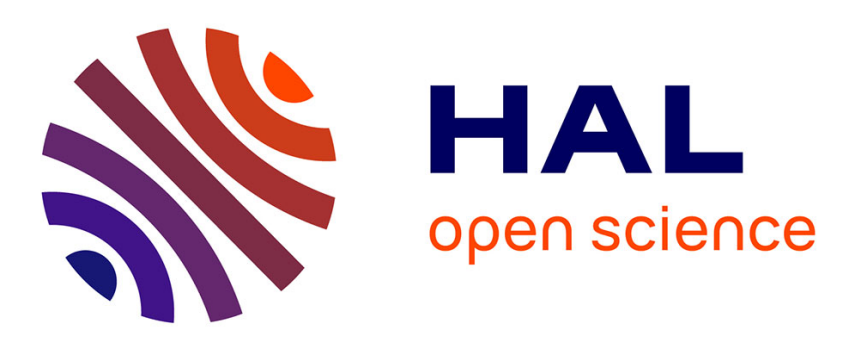

\title{
Acoustic tracking of sperm whales in the Gulf of Alaska using a two-element vertical array and tags
}

Delphine Mathias, Aaron Thode, Jan Straley, Russ D. Andrews

\section{To cite this version:}

Delphine Mathias, Aaron Thode, Jan Straley, Russ D. Andrews. Acoustic tracking of sperm whales in the Gulf of Alaska using a two-element vertical array and tags. Journal of the Acoustical Society of America, 2013, 134 (3), pp.2446-2461. 10.1121/1.4816565 . hal-00865948

\section{HAL Id: hal-00865948 \\ https://hal.science/hal-00865948}

Submitted on 25 Sep 2013

HAL is a multi-disciplinary open access archive for the deposit and dissemination of scientific research documents, whether they are published or not. The documents may come from teaching and research institutions in France or abroad, or from public or private research centers.
L'archive ouverte pluridisciplinaire HAL, est destinée au dépôt et à la diffusion de documents scientifiques de niveau recherche, publiés ou non, émanant des établissements d'enseignement et de recherche français ou étrangers, des laboratoires publics ou privés. 


\title{
Acoustic tracking of sperm whales in the Gulf of Alaska using a two-element vertical array and tags
}

\author{
Delphine Mathias ${ }^{\mathrm{a})}$ and Aaron M. Thode \\ Marine Physical Laboratory, Scripps Institution of Oceanography, University of California San Diego, \\ La Jolla, California, 92093-0238 \\ Jan Straley \\ University of Alaska, Southeast Sitka, Alaska 99835 \\ Russel D. Andrews \\ School of Fisheries and Ocean Sciences and the Alaska SeaLife Center, University of Alaska Fairbanks, \\ P.O. Box 1329, Seward, Alaska 99664
}

(Received 29 June 2012; revised 18 December 2012; accepted 9 January 2013)

\begin{abstract}
Between 15 and 17 August 2010, a simple two-element vertical array was deployed off the continental slope of Southeast Alaska in $1200 \mathrm{~m}$ water depth. The array was attached to a vertical buoy line used to mark each end of a longline fishing set, at $300 \mathrm{~m}$ depth, close to the sound-speed minimum of the deep-water profile. The buoy line also served as a depredation decoy, attracting seven sperm whales to the area. One animal was tagged with both a LIMPET dive depth-transmitting satellite and bioacoustic "B-probe" tag. Both tag datasets were used as an independent check of various passive acoustic schemes for tracking the whale in depth and range, which exploited the elevation angles and relative arrival times of multiple ray paths recorded on the array. Analytical tracking formulas were viable up to $2 \mathrm{~km}$ range, but only numerical propagation models yielded accurate locations up to at least $35 \mathrm{~km}$ range at Beaufort sea state 3 . Neither localization approach required knowledge of the local bottom bathymetry. The tracking system was successfully used to estimate the source level of an individual sperm whale's "clicks" and "creaks" and predict the maximum detection range of the signals as a function of sea state.
\end{abstract}

(C) 2013 Acoustical Society of America. [http://dx.doi.org/10.1121/1.4816565]

PACS number(s): 43.60.Fg, 43.80.Ka [JJF]

Pages: 2446-2461

\section{INTRODUCTION}

\section{A. Motivation for tracking sperm whales in the Gulf of Alaska}

Sperm whales (Physeter macrocephalus) have learned how to remove black cod from deep-water longline gear in the Eastern Gulf Of Alaska (EGOA), and this activity has increased in frequency, severity, and geographic extent over the past decade (Hanselman et al., 2009; Sigler et al., 2008). In 2003, the Southeast Alaska Sperm Whale Avoidance Project (SEASWAP) was created to quantify the scale of this depredation in the EGOA and to recommend strategies to reduce it. Passive acoustic monitoring and bioacoustic tagging became important tools for studying sperm whale behavior during natural and depredation foraging behaviors (Thode et al., 2007; Mathias et al., 2009, Mathias et al., 2012). One key aspect of the study has been determining what acoustic cues alert the animals to fishing activity and over what distance these cues are detectable above background noise levels. Preliminary work found that whales identify demersal longline fishing hauls by the cavitation sounds generated by the engagement/disengagement of the

\footnotetext{
${ }^{\text {a) }}$ Author to whom correspondence should be addressed. Current address: GIPSA-Lab, Grenoble INP, 11 rue des Mathématiques, BP46, $38402 \mathrm{St}$ Martin d'Hères, France. Electronic mail: delphine.mathias@gmail.com
}

vessels' propellers during hauling (Thode et al., 2007). However, determining the ranges over which whales respond to these cues is more problematic, as it requires an acoustic deployment for tracking whale positions over several hours while covering a region of at least 10 miles in radius.

Unfortunately, standard methods for tracking sperm whales using passive acoustics are impractical to use under most practical fishing scenarios as these methods require the deployment of multiple hydrophones separated by hundreds to thousands of meters, a process that absorbs prohibitive amounts of time and increases the chance of losing gear. Similar problems arise when studying depredation of other marine mammal species.

Here we present a passive acoustic tracking method that requires only a single deployment of two hydrophones, attached to the fishing gear itself. The hydrophones, arranged as a vertical array with $10 \mathrm{~m}$ separation, exploit the depthdependent sound speed profile of the cold-water region to detect multipath propagation of sperm whale sounds and thus establish range and depth estimates. The technique may also be viable in more temperate waters as long as a sound speed minimum in the water column exists, although "shadow zones" may arise at certain ranges due to the expected differences between sperm whale foraging depths and the (lower) sound speed minimum in temperature waters.

Section IB reviews previous published work on longrange tracking, and Sec. II describes the 2010 vertical array 
experiment, including tag deployments. Section III explains the tracking methodology and introduces the practical problems encountered when processing real data, and Sec. IV shows how the 2010 deployment was able to track a sperm whale out to $35 \mathrm{~km}$ and then provides simple analytic formulas for the measured transmission loss and estimates the apparent source levels of the same sperm whale at different ranges. Finally, Sec. V discusses the sensitivity of the methods to various uncertainties and estimates the ultimate detection and tracking range of the system as a function of sea state.

\section{B. Previous acoustic tracking research}

The frequent acoustic activity of sperm whales, combined with the high broadband intensity of their impulsive sounds called "clicks," makes them ideal candidates for passive acoustic localization. Clicks can be heard on hydrophones several kilometers from a vocalizing sperm whale (Leaper et al., 1992; Mellinger et al., 2004; Barlow and Taylor, 2005). Multiple ray arrivals (direct, reflected, and refracted paths), dubbed "multipath," can often be differentiated in time, expanding tracking capabilities further (Nosal and Frazer, 2006; Tiemann et al., 2006).

Multipath reflections from the ocean bottom and surface arrive at the receiver at different times and can be treated as data obtained by "virtual" receivers above the ocean surface and incorporated into the solution to improve the accuracy of estimated source positions or to reduce the number of hydrophones required for a solution (Whitney, 1968; Urick, 1983; McDonald et al., 1995; Mouy et al., 2011). Thode (2004) used a two-hydrophone wide-aperture towed array and multipath arrivals for obtaining low-resolution dive tracks of multiple sperm whales.

The newest tracking techniques use numerical acoustic propagation models to account for both ray-refraction and multipath effects generated by realistic depth-dependent sound speed profiles. Measurements of multipath arrival times are compared with modeled arrival times to create an ambiguity surface. Tiemann et al. (2006) demonstrated a three-dimensional localization method for tracking sperm whales using only one acoustic sensor along with a model of the azimuthally dependent bathymetry surrounding the sensor. Nosal et al. (Nosal and Frazer, 2006) developed a modelbased method for exploiting relative arrival time differences between direct and surface-reflected clicks to track a sperm whale in three dimensions, using recordings from five widely spaced bottom-mounted hydrophones at a U.S. naval test range, where the elements were separated by $7.5 \mathrm{~km}$.

Here data from a two-element vertical acoustic array are used to demonstrate that sperm whale long-range tracking can be performed with a single compact deployment without knowledge of the regional bottom bathymetry. The results are independently confirmed by comparing the method's range and depth estimates with location and depth information provided from a tagged sperm whale. The whale was originally tagged within a few hundred meters of the array, and then over 2 days traveled $80 \mathrm{~km}$ away under constant weather conditions, providing an ideal scenario for observing and understanding the performance of the tracking system with increasing range.

\section{DATA COLLECTION}

\section{A. Vertical array deployment}

Between 15 and 17 August, 2010, the F/V Northwest Explorer deployed a two-element vertical array in $1200 \mathrm{~m}$ water depth at the Spencer Spit (57.8115 N, -137.4043 W) on the southeastern Alaskan continental slope (Fig. 1). The array was composed of two acoustic recorders, attached at $300 \mathrm{~m}$ depth to a buoy line, used to mark ends a demersal longline fishing set, and separated by $10 \mathrm{~m}$ vertically (Fig. 2). Each recorder used a Persistor CF2 data acquisition system and a HTI-96 min hydrophone (High-Tech Inc.) with a sensitivity of $172 \mathrm{~dB}$ re $1 \mu \mathrm{Pa} / \mathrm{V}$. The calibration values are from High Tech Inc. measurements of the individual sensors before shipping. These laboratory values were checked in the field by comparing the received level of a FM sweep of known source level at known range in deep water with theoretical predictions. After an analog voltage amplification of 26 ( $28 \mathrm{~dB}$ gain), the data were written to a $2.5 \mathrm{~V} \mathrm{~A} / \mathrm{D}$ converter. Thus the system could record peak-to-peak impulses of $153 \mathrm{~dB}$ re $1 \mu \mathrm{Pa}$ (pp) without clipping. The Persistor system would log data to a $4 \mathrm{~Gb}$ flash memory card for $10 \mathrm{~h}$, then stop sampling for $2 \mathrm{~h}$ to transfer the data to a hard disk. Onset's HOBO Pendant G data loggers were taped inside each recorder to monitor the system's vertical inclination by measuring the three-dimensional angular displacement every minute. Two Sonotronics acoustic pingers were attached $1 \mathrm{~m}$ above each unit. Every $30 \mathrm{~s}$ each pinger emitted a $10 \mathrm{~ms}$ pulse at $10 \mathrm{kHz}$; this was used to time synchronize the acoustic data (Sec. III). A Seabird SBE39 was deployed between the acoustic recorders, providing pressure and temperature measurements every minute. During deployment and recovery, the SBE39 also provided a temperature profile of the water column to $300 \mathrm{~m}$ depth. Furthermore, the pressure data helped assess the gross vertical stability of the array deployment, and the temperature data helped assess the environmental stability over the 2 days of the deployment because large temperature changes would affect the sound speed profile and thus the sound propagation in the area. A $30 \mathrm{~kg}$ lead cannonball was placed below all instruments to keep the system as vertical as possible throughout the deployment. This instrumental configuration was easy to attach and deploy using standard longline fishing techniques.

Prior to the vertical array deployment, the same Seabird SBE39 mentioned in the previous paragraph was attached about $3 \mathrm{~m}$ above a $30 \mathrm{~kg}$ anchor and cast into the water where it measured the temperature and pressure every second down to $475 \mathrm{~m}$ depth. The Mackenzie equation (1981) was used to derive the sound speed in sea water as a function of temperature, salinity, and depth. The salinity was assumed to be 32.4 psu at all depths based on the World Ocean Atlas (Antonov et al., 2010), and the temperature was assumed constant below $475 \mathrm{~m}$. Figure 3(a) displays the resulting sound speed profile and reveals that the local sound speed minimum lies close to $300 \mathrm{~m}$. This depth was selected for the subsequent array deployment in the anticipation that some of the sound generated by the deep-diving animals would refract toward the sound speed channel with minimum surface or bottom interactions, thus minimizing its 


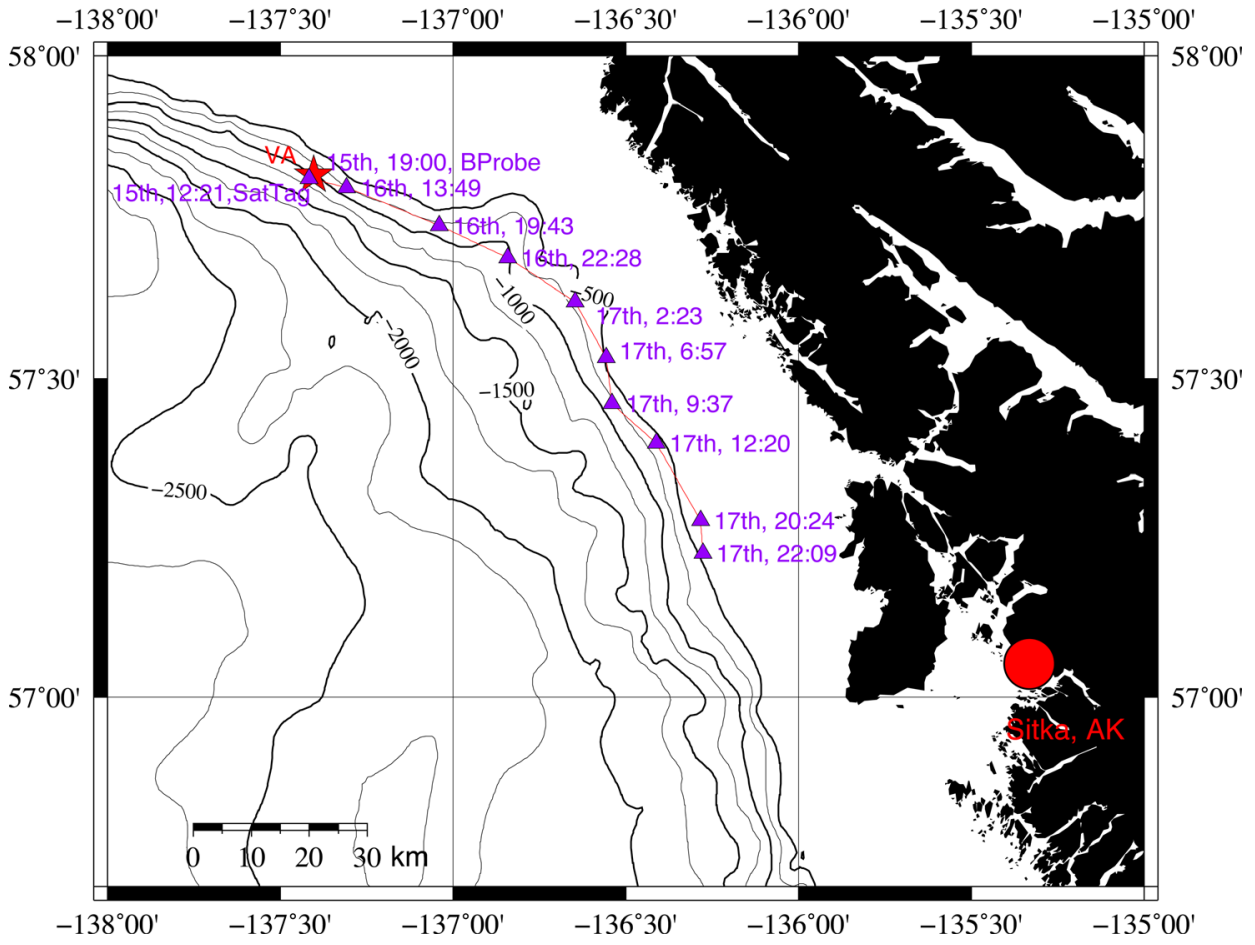

FIG. 1. (Color online) Contour map (depth in meters) of the study area, showing Sitka (circle) and the vertical array deployment (star). The vertical array deployment occurred at 57.8160 $\mathrm{N}$ and $137.4037 \mathrm{~W}$. The whale was tagged $1.4 \mathrm{~km}$ away from the vertical array on 15 August 2010 at 12:21 and was $80 \mathrm{~km}$ away on 17 August 2010 at 12:20. The LC1 and LC2 satellite locations of the tagged whale during the vertical array deployment are marked with triangles. The accuracy of these satellite positions is $\pm 1.2 \mathrm{~km}$.

transmission loss and increasing the potential detection range. A second cast was made at the end of the experiment (3 days later) and revealed a very similar sound-speed profile. The average sound speed variation between the two casts was less than $0.1 \mathrm{~m} / \mathrm{s}$.

\section{B. Satellite and bioacoustic tagging}

During the same trip that the array was deployed, tags in the low impact minimally percutaneous external-electronics transmitter (LIMPET) configuration (Andrews et al., 2008) were also deployed several times from a small boat launched by the F/V Northwest Explorer. The LIMPET Mk10-A tags were deployed between 6 to $10 \mathrm{~m}$ from a whale using a pneumatic rifle and were attached with two barbed titanium darts that penetrated $6.5 \mathrm{~cm}$ into the dorsal ridge. The tags were based on the Wildlife Computers Mk10-A, which is able to $\log$ and transmit detailed information on diving behavior. The tags were programmed to transmit a low resolution time series of dive depth measurements taken every $2.5 \mathrm{~min}$; however, for every dive, they also transmit higher resolution data on the maximum dive depth (1-2\%

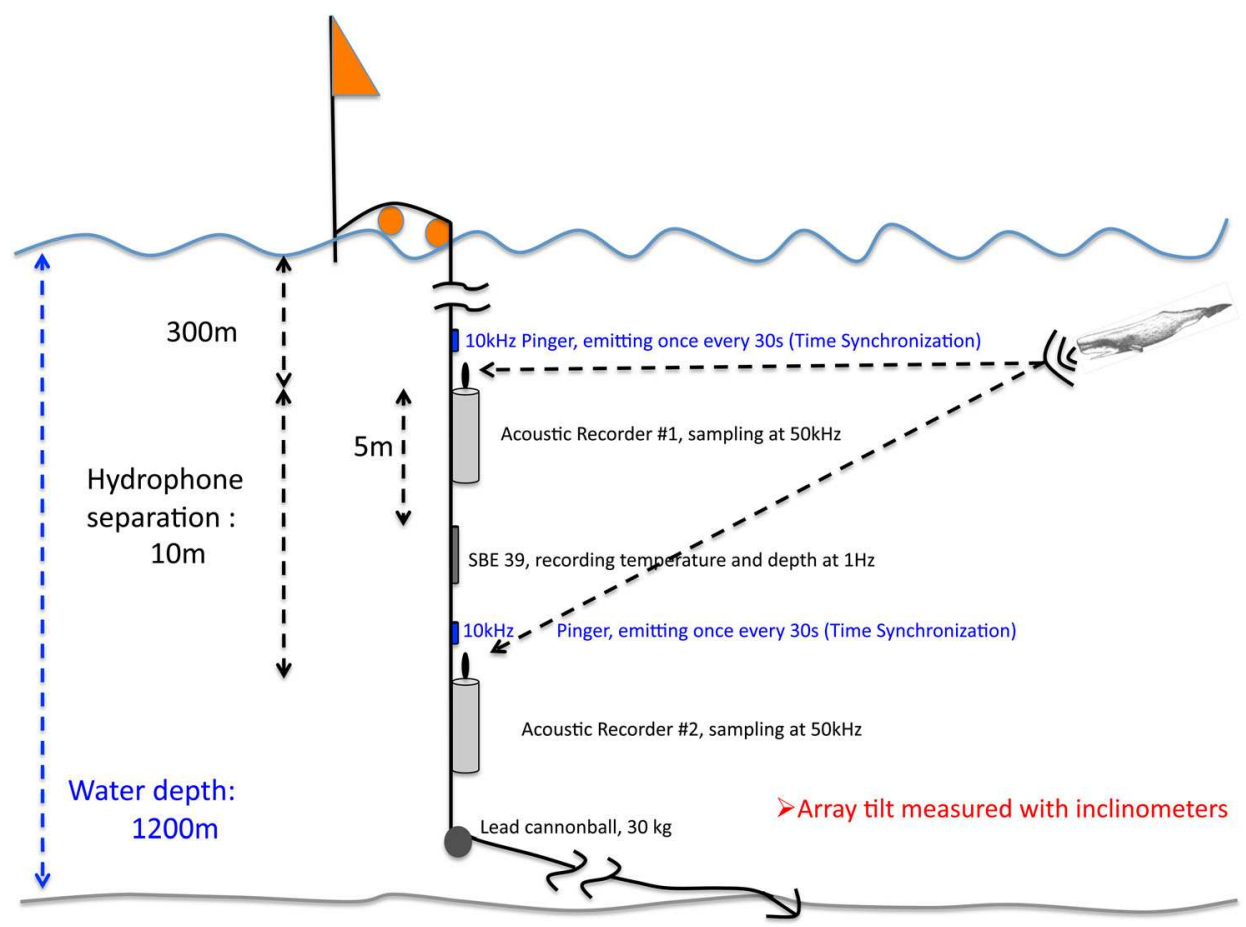

FIG. 2. (Color online) Schematic of vertical array deployed on 15 August 2010 at 12:00 and recovered on 17 August 2010 at 8:45. The surface flag, buoyline, vertical line, and anchor served as a longline decoy for sperm whales. 

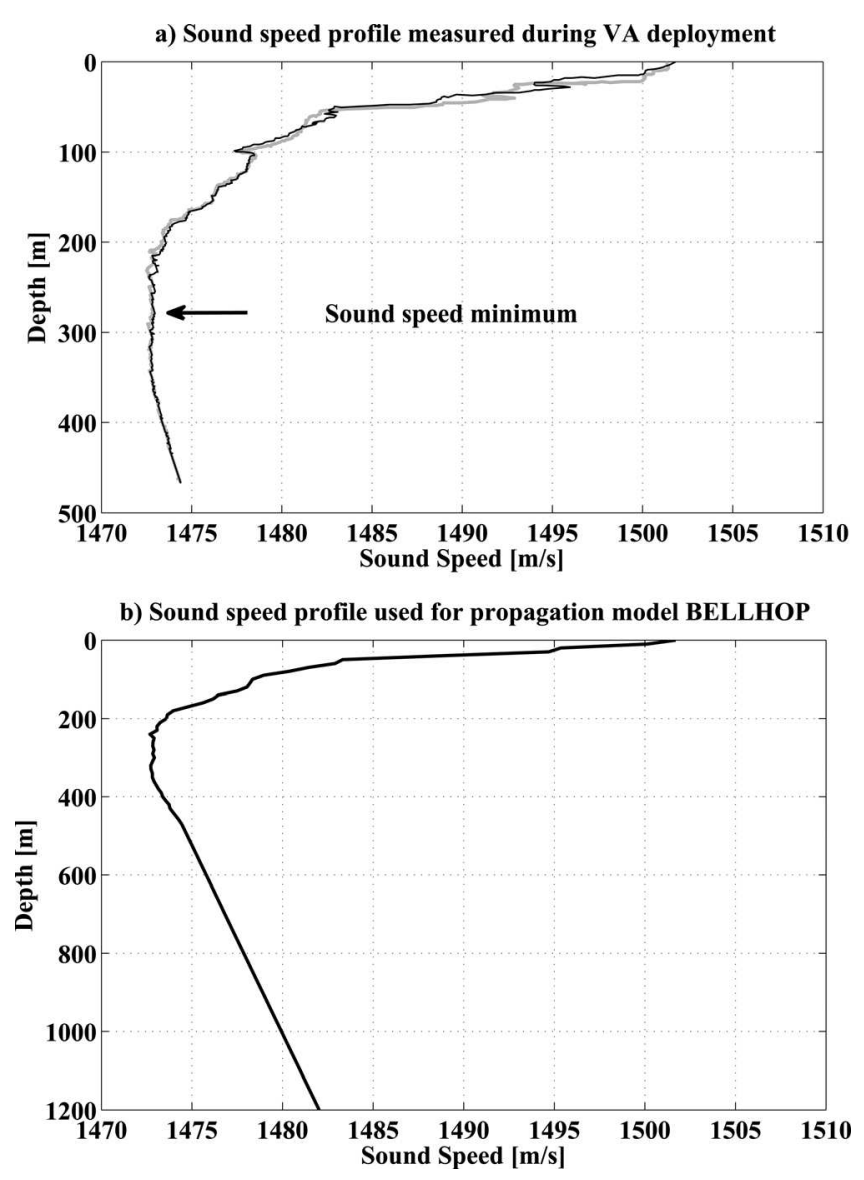

FIG. 3. (a) Sound speed profile derived from a temperature-depth downcast (black line) and upcast (gray line) taken before the vertical array deployment. The Mackenzie equation (1981) was used to derive the sound speed in sea water as a function of temperature, salinity, and depth, where the salinity was assumed to a uniform 32.4 psu over depth based on historical databases (Sec. II A). (b) Sound speed profile used in propagation model BellHOP. The profile is derived from the sound speed profile of top panel for depths above $450 \mathrm{~m}$ and linearly interpolated for depths below $450 \mathrm{~m}$.

resolution), dive duration, overall dive profile shape, and post-dive surface interval, provided that enough surface time is available for transmitting the data via the Argos-system. Geographic locations of tags were determined by Service Argos (CLS America) using the Doppler shift created by the satellite passing overhead.

Satellite tag location data were filtered using the Douglas ARGOS-FILTER version 8.2 (http://alaska.usgs.gov/science/ biology/spatial/douglas.html). This filter includes a number of user-defined variables: Maximum-redundant-distance (consecutive points separated by less than a defined distance are kept by the filter because ARGOS location errors rarely occur in the same place, so very close temporally consecutive points are assumed to be self-confirming); location classes (LCs) that are automatically retained; maximum sustainable rate of movement; and the rate coefficient (Ratecoef) for assessing the angle created by three consecutive points. The rate coefficient algorithm takes into account that the further an animal moves between locations, the less likely it is to return to or near to the original location without any intervening positions, creating an acute angle characteristic of a typical ARGOS error. We automatically retained locations separated from the next location by less than a maximum redundant distance of $3 \mathrm{~km}$, as well as any LC2 and LC3 locations (estimated error of $<500$ and $<250 \mathrm{~m}$, respectively; ARGOS User's Manual). LC1 locations (with estimated error of between 500 and $1500 \mathrm{~m}$ ), as well as LC0, LCA, LCB, and LCZ locations (with no estimation of accuracy), were only retained if they passed the Douglas ARGOS-FILTER process. For maximum sustainable rates of movement, we used $9 \mathrm{~km} \mathrm{~h}^{-1}$. We used the default Ratecoef for marine mammals (Ratecoef $=25$ ). The satellite tag locations used in this study were LC1 and LC2 locations with accuracies within $1.2 \mathrm{~km}$, using the 68th percentile ARGOS location error measured by Costa et al. (2010).

A high-resolution digital bioacoustic "B-probe" sampling tag (Burgess et al., 1998; Goldbogen et al., 2006; Oleson et al., 2007) was also attached to a whale during the experiment, $6.65 \mathrm{~h}$ after that whale was tagged with a LIMPET dive depth-transmitting tag. Besides sampling acoustic data, the B-probe contains a pressure sensor and a two-axis accelerometer (MXA2500GL, Memsic Inc., North Andover, MA) with one axis parallel to the longitudinal axis of the probe. Data from the depth gauge and accelerometers were sampled at $1 \mathrm{~Hz}$ and stored within the tag. The tag was attached to the animal via two suction cups and deployed using a modified $10 \mathrm{~m}$ graphite windsurfing pole. The acoustic tag data analyzed in this paper were sampled at $4096 \mathrm{~Hz}$, sufficient for detecting sperm whale regular clicks and creaks (Mathias et al., 2012).

Sperm whales often wait at the buoy lines for gear to be retrieved, and at least seven sperm whales were sighted close to the vertical array during the 2-day experiment. At 12:21 on 15 August 2010, one whale was tagged with a LIMPET satellite tag $1.4 \mathrm{~km}$ away from the vertical array and was later tagged at 19:00 with a B-probe suction cup tag $300 \mathrm{~m}$ away from the vertical array. The tagged whale was recognized as "GOA 025" and had been sighted in 2003 and 2004 close to fishing vessels in the Sitka fishing area. This whale will subsequently be referred as "the tagged whale" in the text. The B-probe stayed on the tagged whale for $2.5 \mathrm{~h}$ and provided high resolution acoustic, depth, and orientation data for three complete dives. Figure 4(a) displays the whale's dive profile recorded by the B-probe during those three dives with the lower-resolution LIMPET tag data overlain on top. The LIMPET satellite tag continued to transmit location and depth data until 30 August 2010, when it was $1000 \mathrm{~km}$ south from the original tagging site. Figure 4(b) displays the whale's dive profile and range provided by the satellite tag data during the vertical array experiment (15-17 August 2010).

\section{LOCALIZATION METHODS}

The two autonomous recorders in the array were time synchronized to within a millisecond by placing two Sonotronics acoustic pingers $1 \mathrm{~m}$ above each unit. Every 30 $\mathrm{s}$, each pinger emitted a $10 \mathrm{~ms}$ pulse centered around $10 \mathrm{kHz}$. The data were synchronized every $5 \mathrm{~min}$ throughout the 2-day deployment. The initial offset between the top unit and the bottom unit was determined to be $0.419 \mathrm{~s}$, and the measured linear clock drift was $26 \mathrm{~ms} / \mathrm{h}$ (or $0.624 \mathrm{~s} /$ day). 

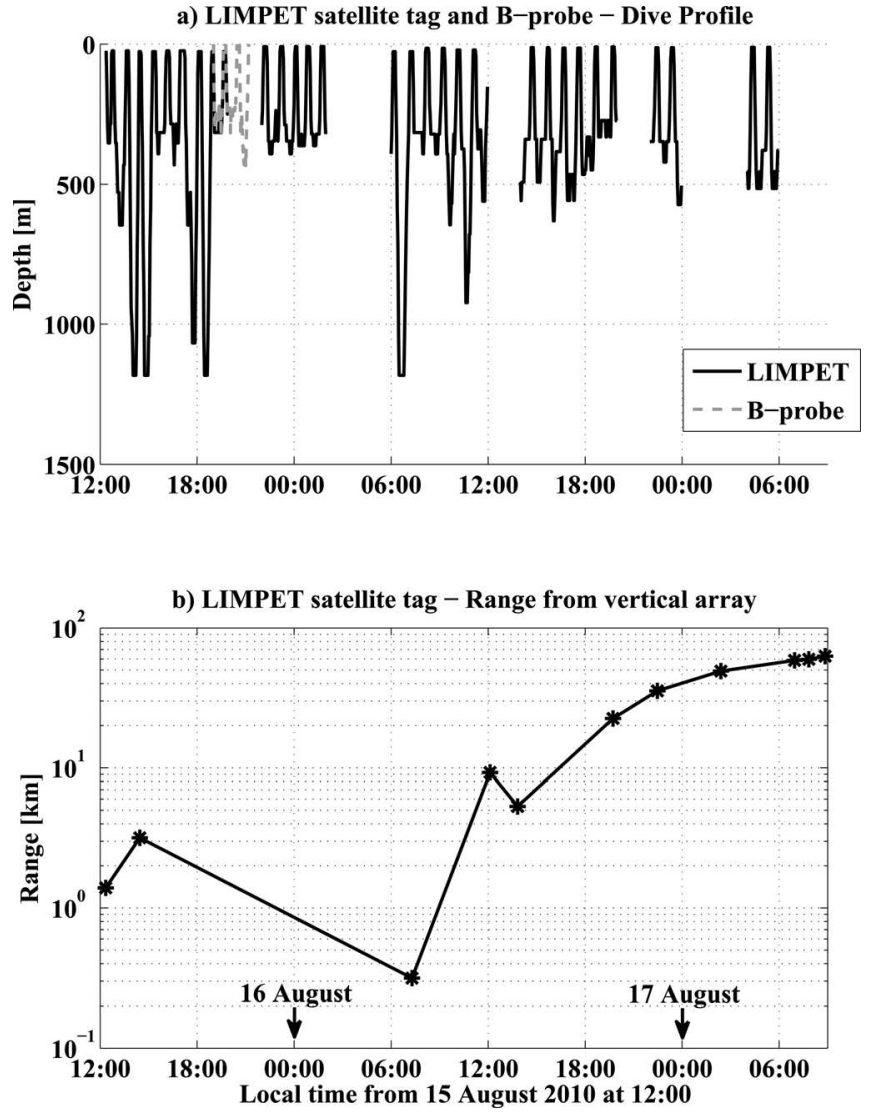

FIG. 4. (a) Sperm whale dive profiles from the LIMPET satellite tag and Bprobe. (b) Range of whale from vertical array, using ARGOS locations transmitted from the LIMPET tag.

\section{A. Acoustic parameter extraction from array using satellite and bioacoustic tag data}

\section{Extracting ray path arrival times on a single hydrophone}

Each click "event" generated by a sperm whale can arrive on a hydrophone via multiple ray paths. In this paper, the ray path that arrives first on a hydrophone will be dubbed the "primary" path, and other ray path arrivals that arise from the same click event are dubbed "secondary" paths, or "multipath." Localizing a sperm whale requires measuring the relative arrival times of all click event ray paths on both vertical array hydrophones. Because multiple sperm whales were generally present in the area and simultaneously vocalizing, the tagging data were needed to help flag the tagged whale click trains and their associated multipath arrivals in the vertical array acoustic data where a click train is defined here as a temporal sequence of primary path arrivals from the same animal that contain no interruptions greater than a couple of seconds. The satellite tag data provided the start time of most of the dives, and a sperm whale usually starts clicking within 2 min of the start of a dive, so the satellite tag data could be used to estimate when the tagged whale's initial click train would appear in the vertical array data. Three different techniques were then used to extract the tagged whale data from each array hydrophone, depending on the number of other whales present and whether bioacoustic tag (B-probe) sound data were available at short ranges. When only a few whales were vocalizing, a manual inspection of the spectrograms was sufficient for flagging the start of the tagged whale's new click train. The multipath arrival times were then manually extracted on both array hydrophones over a $20 \mathrm{~s}$ time series window. This step was time consuming (taking up to $10 \mathrm{~min}$ for each click train) and would need to be automated for real-time applications using a combination of rhythmic analysis and crosscorrelation techniques (e.g., Baggenstoss, 2011).

At earlier times and closer ranges, several whales were clicking, complicating the tracking task because the tagged whale was not producing the most intense click trains. Under these circumstances, a simple "energy" detector was applied to the vertical array acoustic data by generating a series of $512 \mathrm{pt}$ Fast Fourier transforms (FFTs) (0.0102 s window), overlapped $75 \%$, integrating the power spectral density between 5000 and $9000 \mathrm{~Hz}$, and subtracting a running average of the background noise level. This frequency range excluded vessel noise (below $4 \mathrm{kHz}$ ) and pinger pulses $(10 \mathrm{kHz})$. The detection threshold on the array data was set to $5 \mathrm{~dB}$. By stacking the time series of all detected events as a waterfall plot, it became possible to identify the click train of a whale that had just begun vocalizing while starting its descent from the surface (Fig. 5). The reason this is possible is that the secondary ray path is merged with the primary path when the animal is near the surface, but the relative arrival time differences between those two paths gradually

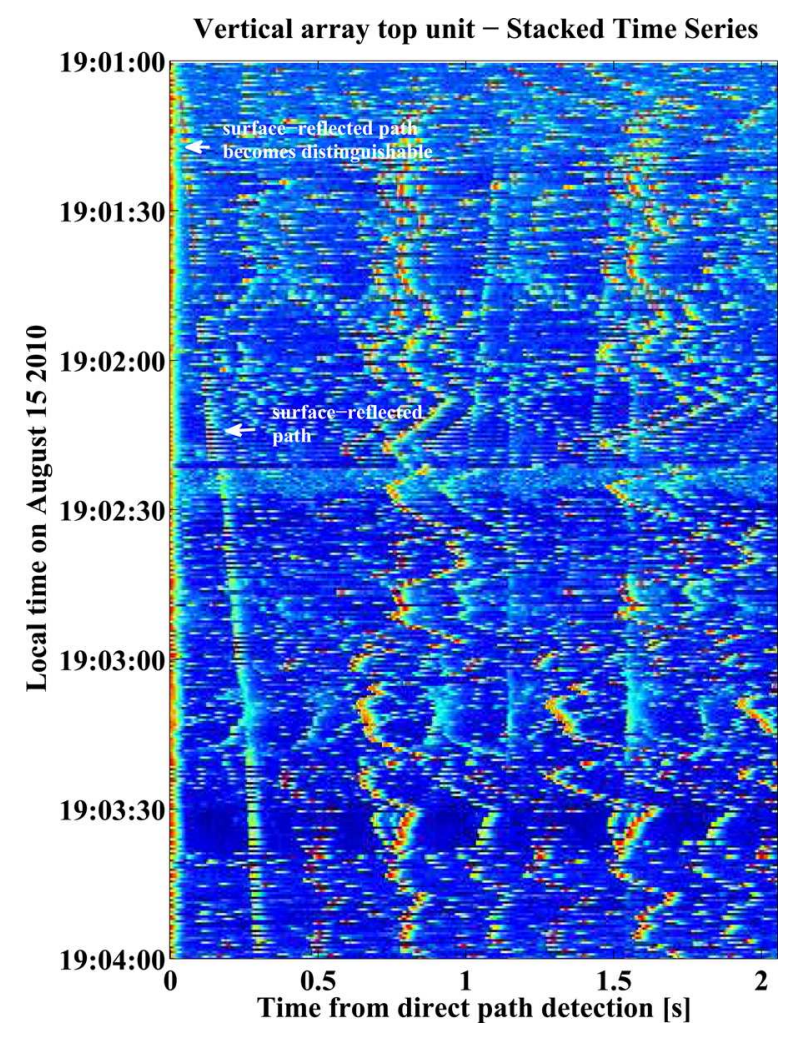

FIG. 5. (Color online) Waterfall plot of the corresponding stacked multipath arrival patterns on the top acoustic recorder of the vertical array between 19:01 and 19:04 on 15 August 2010. The surface-reflected path (indicated by a white arrow) is merged with the direct path at the start of the dive, but as the whale gets deeper, the relative time arrival difference between those two paths gradually grows until they can be visually separated on the stacked waterfall plot at 19:01:10. 
grows as the whale gets deeper until the two paths can be visually separated, creating a distinctive pattern in the waterfall plot. Once this separation occurs, all multipath arrivals were then manually extracted by plotting $20 \mathrm{~s}$ of the filtered time series, starting from the time when the secondary path becomes distinguishable from primary direct path. This technique permitted consistent multipath arrival patterns to be extracted from the tagged whale in the presence of multiple animals.

Finally, at very close ranges to the vertical array bioacoustic tag data were also available and were used to determine when the tagged whale began a dive and when each of its click trains began and ended. The presence of acoustic data from the tag permitted the tagged whale click trains to be flagged across an entire dive and not just over a $20 \mathrm{~s}$ window. The B-probe acoustic data were also used to identify creaks produced by the tagged whale, which were later used to estimate creak source levels (Sec. IV C 2).

Regardless of the exact procedure used, the final analysis result was the same: All primary paths and associated multipath from the tagged whale were extracted on both array hydrophones over at least a $20 \mathrm{~s}$ window, selected a few minutes after the satellite tag (or Bprobe) reported the start of a dive. The following section discusses how these arrivals were matched between array hydrophones.

\section{Computing elevation angles of all ray path arrivals}

Once all ray paths from a click were flagged on the top array hydrophone, matching arrival times needed to be found on the bottom hydrophone. For each click's primary path arrival, a $0.4 \mathrm{~s}$ time series segment (centered on the primary arrival time) from the top hydrophone was cross-correlated with $2 \mathrm{~s}$ of data from the bottom hydrophone time series, and the time lag of the maximum cross-correlation was selected. Because the relative arrival times of additional multipath on the bottom hydrophone have already been computed, the relative arrival times of all ray paths between the hydrophones are then readily deduced. The relative arrival time difference of a given ray path arrival in seconds, TDOA multipath, translates into a vertical arrival angle $\alpha_{\text {multipath }}$ (in radians) if the element separation is known

$$
\alpha_{\text {multipath }}=\operatorname{asin}\left(\frac{c_{\text {water }} \text { TDOA } A_{\text {multipath }}}{D}\right)
$$

where $c_{\text {water }}$ is the sound speed, set to $1475 \mathrm{~m} / \mathrm{s}$, and $D$ is the hydrophone separation, which was $10 \mathrm{~m}$. The expected angular resolution is $0.7^{\circ}$ at $15 \mathrm{kHz}$ (short ranges), while at larger ranges, the higher frequency components get stripped from the signal, yielding a typical frequency of $6 \mathrm{kHz}$, which provides a lower resolution of $1.7^{\circ}$.

\section{B. Tracking algorithms}

At ranges close to the vertical array, the acoustic multipath arrives at steep angles and thus does not refract much through the water column. At very close ranges (less than $2 \mathrm{~km}$ ), the surface- and bottom-reflected paths from a click can be isolated in time from the direct path received on one hydrophone, and the whale's depth and range from a single hydrophone can be determined (Thode et al., 2002). However, the technique only works over short ranges and requires considerable knowledge of the regional bathymetry. If two hydrophones are available, the requirement of a third propagation path (e.g., bottom-reflected path) can be eliminated; only a second (e.g., surface-reflected) path is required, eliminating the need for independent knowledge of the local bathymetry (Thode et al., 2002). Unfortunately, as shown in the results, the validity of the rectilinear assumptions behind the analytical formulas become invalid at relatively short ranges.

The use of a numerical ray-tracing algorithm should be viable at all source ranges and depths provided that an accurate sound speed profile is used, and a propagation grid size of sufficient resolution $(\Delta r=10 \mathrm{~m}, \Delta z=10 \mathrm{z})$ is selected (e.g., Tiemann et al., 2006). The grid size was deemed "sufficient" if one found that increasing the resolution of the grid by a factor of two led to no substantial change in the predicted arrival times and angles of the ray arrivals. A key advantage of numerical modeling is that it can account for variations in sound speed over depth and range, thus eliminating the systemic errors from the rectilinear assumptions and capturing additional ray paths not predicted by them (e.g., rays trapped in the sound-speed minimum channel and rays that refract, instead of reflect, from the surface). In this work, it has been assumed that the depth-dependent sound speed profile changes little over a $40 \mathrm{~km}$ radius around the receiver. This assumption is based on the observation that the oceanographic features surrounding the deployment, including surface temperature, water mass, known currents, etc., did not change substantially over this horizontal scale. An additional advantage of numerical modeling is that a given ray path does not need to be flagged as a direct, surface-reflected, or bottom-reflected path in the data, a task that can be difficult when multiple animals are vocalizing simultaneously.

The model-based localization algorithm requires three fundamental steps. First, the relative multipath arrival times and arrival angles must be extracted from the recorded acoustic data as already discussed in Sec. III A. Second, a numerical propagation model must be configured to generate simulations of the viable ray paths with a set of acoustic sources placed on a range-depth grid in a realistic propagation environment. Every candidate location generates a series of predicted relative ray path arrival times and vertical arrival angles, often dubbed "replicas" in the tracking literature. Finally, the measured and modeled arrival patterns are compared to generate an "ambiguity surface," which provides a visual representation of the most probable whale position relative to the array as a function of range and depth. These last two steps are now reviewed in detail.

\section{Replica generation}

The Gaussian beam-tracing acoustic propagation model BELLHOP (Porter and Bucker, 1987) was used to simulate the relative arrival times and angles of ray paths received by a hydrophone for hypothetical sources located at various 
depths and ranges(Tiemann et al., 2004; Tiemann et al., 2006; Nosal and Frazer, 2006; Nosal and Frazer, 2007). While the model can also incorporate range-dependent effects, a single range-independent sound speed profile was used [Fig. 3(b)] based on the sound speed profile measured during the vertical array deployment [Fig. 3(a)] as discussed in Sec. II A. Given the lack of additional environmental data, assuming range independence is reasonable given that the scale of variability of oceanographic features in this region is tens to hundreds of kilometers, at least in regions not adjacent to large straits of the Inside Passage (e.g. Chatham Strait).

Simulated sources were spaced every $10 \mathrm{~m}$ in depth down to $1200 \mathrm{~m}$ and every $10 \mathrm{~m}$ in range out to $40 \mathrm{~km}$ range from the receiver, which was modeled at $300 \mathrm{~m}$ depth. For each candidate location 200000 rays were launched because a fine angular sampling is required to solve for "eigenrays," or ray paths connecting a given source and receiver. The centerline of the Gaussian ray bundle had to pass within $5 \mathrm{~m}$ of the receiver to be counted as an eigenray. The model assumed a source frequency of $6000 \mathrm{~Hz}$, the averaged peak frequency of clicks recorded on the vertical array over the 3-day experiment. (A frequency is required by the raytracing algorithm to model how the effective width of the propagating Gaussian beam "diffuses" over range, but the model output is relatively insensitive to the frequency chosen.)

The model outputs the travel times of all eigenrays that connect a candidate source position, including any paths reflecting from the surface and bottom. For every eigenray, the model also provides the transmission loss and vertical launch and arrival angles. Bottom-reflected paths were excluded from the output because the bottom depth is only known precisely at the vertical array location, and the bottom bathymetry is highly variable in the area. Besides, bottom-reflected paths quickly disappear at larger ranges (Sec. IV A 1) so any long-range tracking method needs to exclude bottom-interacting multipath from consideration.

\section{Producing an ambiguity surface using "scoring"}

The ambiguity surface is a two-dimensional function that displays some metric of similarity between the modeled and measured ray paths as a function of range and depth locations along a vertical grid extending from the array location, which defines the origin of the range axis. The scoring method discussed here for producing the ambiguity surfaces was inspired by Tiemann et al. (2006) but has been extended to incorporate elevation angle information along with relative arrival time.

The score for each candidate source position was obtained by counting the number of modeled eigenrays from that position that share the following characteristics with the measured data: The same relative arrival time, to within 5 $\mathrm{ms}$; and the same vertical elevation angle, to within $1^{\circ}$. These tolerances were derived from the average standard deviation of the measured arrival times and arrival angles of 10 sets of 10 consecutive clicks, selected from times spanning the entire 2-day deployment. Excess arrival ray paths in the modeled data are not penalized. The maximum possible score is $2 M-1$, where $M$ is the number of ray paths per click event in the measured data. This scoring process was repeated for all candidate source positions, and the scores were assembled into ambiguity surfaces. High scores indicate more likely source positions.

\section{Producing an ambiguity surface using weighted mean-square error}

Another approach for creating an ambiguity surface is to compute the mean-square error (MSE) between the measured and modeled relative arrival times (Nosal and Frazer, 2007). The present case also requires the inclusion of the measured and modeled arrival angles, which requires a more complex normalization procedure.

Two different MSE strategies were studied. First, the weighted mean-square error $L_{W M S}$ at each point of the grid $(r, z)$ was computed for the first and second arriving measured ray paths $i$ and $j$, using every possible combination of modeled non-bottom interacting ray paths $A$ and $B$

$$
L(i, j, r, z)_{W M S}=\min _{A, B}\left[\sum_{k=1}^{3} L_{k}(i, j, r, z)\right]
$$

with

$$
\begin{aligned}
& L_{1}(i, j, r, z)=\left[\frac{d \tilde{T}_{A, B}(r, z)-d T_{i, j}}{\sigma_{\text {time }}}\right]^{2}, \\
& L_{2}(i, j, r, z)=\left[\frac{\tilde{\alpha}_{A}(r, z)-\alpha_{i}}{\sigma_{\text {angle }}}\right]^{2}, \\
& L_{3}(i, j, r, z)=\left[\frac{\tilde{\alpha}_{B}(r, z)-\alpha_{j}}{\sigma_{\text {angle }}}\right]^{2},
\end{aligned}
$$

where $d \tilde{T}_{A, B}(r, z)$ is the arrival time difference between a particular $A$ and $B$ modeled ray path set on the top hydrophone, generated from location $(r, z), d T_{i, j}$ is the measured arrival time difference between two multipath arrivals $i$ and $j$ on the top hydrophone, and $\tilde{\alpha}_{A}(r, z)$ and $\tilde{\alpha}_{B}(r, z)$ are the modeled elevation angles of candidate $A$ and $B$ paths originating from location $(r, z), \alpha_{i}$ and $\alpha_{j}$ are the measured elevation angles of $i$ and $j$, while $\sigma_{\text {time }}$ is the estimated standard deviation of the measured arrival time differences, and $\sigma_{\text {angle }}$ is the estimated standard deviation of measured elevation angles. $\sigma_{\text {time }}$ was set to $5 \mathrm{~ms}$ and $\sigma_{\text {angle }}$ was set to $1^{\circ}$.

In Eq. (2a), the three parameter error terms (two angles, one relative arrival time) are summed together and then the modeled arrival combination $A$ and $B$ that minimizes $L$ is selected. If more than three measured ray paths were ever detected, Eq. (2a) could be modified to minimize over all the possible pairwise combinations of $i$ and $j$ as well. However, in the results presented here, no tertiary arrivals were ever detected. Dividing each individual error term in $L$ by its standard deviation lowers the weight of components with a high variance relative to the mean. The relative standard deviation of the measured arrival angles $\sigma_{\text {angle }}$ is larger than the relative standard deviation of the measured arrival time 
differences $\sigma_{\text {time }}$, so the arrival time measurements dominate the final error $L_{W M S}$.

An alternative normalization $L_{N M S}$ achieves more equal weighting between angles and arrival times by dividing the normalized errors by the maximum error encountered in the simulation for that term. Thus Eq. (2a) becomes

$$
L(r, z)_{N M S}=\min _{A, B}\left[\sum_{k=1}^{3} \hat{L}_{k}(i, j, r, z)\right]
$$

with

$$
\hat{L}_{k}(i, j, r, z)=\frac{L_{k}(i, j, r, z)}{\max _{r, z}\left[L_{k}(i, j, r, z)\right]},
$$

where $\max _{r, z}\left[\mathrm{~L}_{\mathrm{k}}\right]$ is the maximum value of $L_{k}$ encountered when modeling all candidate source ranges and depths. A potential weakness of this approach is that the value of Eq. (3a) might thus change depending on the range and depth intervals modeled; as a practical matter, the maximum values of a given term $L_{k}$ are relatively insensitive to the span of the model parameter space because much of the range in variation of the modeled $L_{k}$ arises from changes in modeled source depth not range. Thus the span of ranges modeled generally has little effect on the denominator of Eq. (3b).

Low values of $L_{N M S}$ or $L_{W M S}$ in the ambiguity surface indicate more likely positions, in contrast to the scoring ambiguity surfaces, where the global maximum indicates the likeliest position.

\section{Click received levels as a function of range}

As discussed by Madsen (2005), different metrics are commonly used in bioacoustics to report the intensity of transient signals in water, leading to levels varying by as much as $15 \mathrm{~dB}$ for the same signal. The received levels of clicks emitted by the tagged whale at known ranges were measured using three metrics. First, the peak-to-peak (pp) sound pressure level (SPL) (in $\mathrm{dB}$ re $1 \mu \mathrm{Pa}$ ) was selected from the click waveform, filtered between 2 and $25 \mathrm{kHz}$. Second, the root-mean-squared (rms) sound pressure level (in $\mathrm{dB}$ re $1 \mu \mathrm{Pa}$ ) was estimated (Urick, 1983) over the duration of the waveform that comprised $90 \%$ of the cumulative equalized sound exposure level values in the time series incorporating the click (Malme et al., 1986; Madsen, 2005). Finally, the sound exposure level (SEL) of the transient was computed over the same portion of the waveform, using the same duration used for the rms level estimate. In Sec. IV, received levels $(\mathrm{RL})$ for clicks emitted at known ranges are combined with modeled transmission losses to estimate the tagged sperm whale's source levels over time.

\section{RESULTS}

Even though several whales were present in the area, the particular results shown here only concern the one tagged with satellite and bioacoustic instruments within $300 \mathrm{~m}$ of the vertical array, thereby providing independent estimates of the whale's position and indicating the accuracy of the analytical and numerical passive acoustic tracking techniques as the whale moved away from the array.

\section{A. Localization results}

\section{Depth and range tracking at ranges less than $2 \mathrm{~km}$}

The first set of depth and range localizations were computed immediately after the whale was tagged with the B-probe tag on 15 August 2010 at 19:00. The two-hydrophone analytical method and the model-based NMS and WMS methods provided accurate depth and ranges estimates during the first B-probe dive [Fig. 6(a)]. Both methods also indicated that the whale came very close to the vertical array (within $50 \mathrm{~m}$ at 19:05) and then started to steadily swim away. By the end of the first B-probe dive, the whale had swum approximately $1.6 \mathrm{~km}$ away from the array.

The whale was at about $2 \mathrm{~km}$ range at the start of the second B-probe dive at 19:46. By this point, the bottomreflected path had disappeared from the vertical array acoustic data. The depth estimates provided by the twohydrophone analytical method became inaccurate: The depth error was $40 \mathrm{~m}$ for a $220 \mathrm{~m}$ whale depth at 19:51 [Fig. 6(b)]. Thus rectilinear propagation assumptions became invalid for ranges greater than $2 \mathrm{~km}$ in this environment, and ray
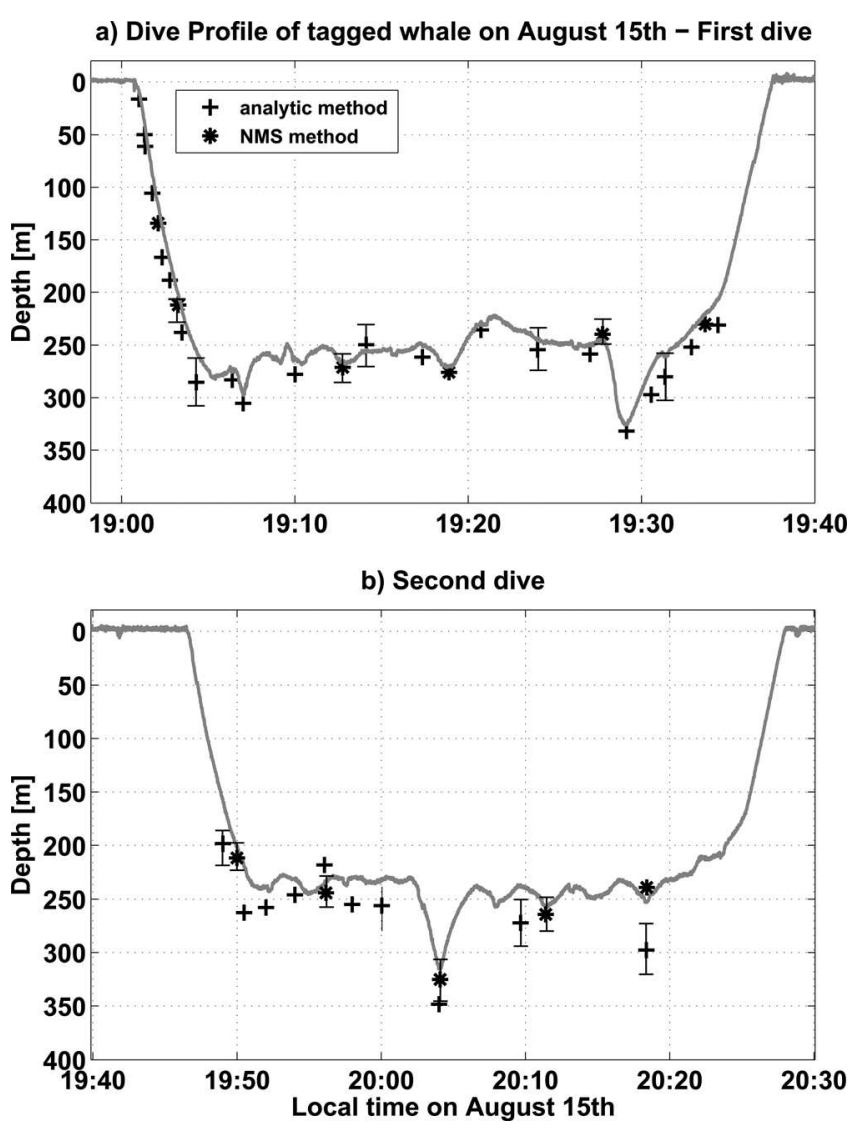

FIG. 6. (a) First and (b) second dive profiles of the tagged whale recorded by the B-probe on 15 August 2010 (gray solid line). Depth estimates using the analytical two hydrophone method (Sec. III B) are marked with crosses. Depth estimates using the NMS method [Sec. III B 3, Eqs. (3a) and (3b)] are marked with stars. The WMS method provides the same result as the NMS method. 
refraction effects need to be treated with numerical models beyond these ranges. For example, the depth estimates provided by the model-based NMS method compare favorably with the tag depth data during the second dive [Fig. 6(b)]. The WMS results were identical to the NMS results.

\section{Depth and range tracking at ranges greater than $2 \mathrm{~km}$}

The B-probe released from the whale after only $2.5 \mathrm{~h}$, so detailed depth data are unavailable after 15 August 2010 at 21:00. The next reported satellite position of the tagged whale was $400 \mathrm{~m}$ from the array at 7:17 the following morning, and this range then increased over the next 2 days. Figure 7 shows spectrograms of signal samples at ranges of $2,5,8,22$, and $35 \mathrm{~km}$ from the vertical array (as indicated by the satellite tag data), in units of power spectral density. Figures 8(a)-10(a) show the ambiguity surfaces created using the scoring method described in Sec. III B 2, using the data samples from 5, 22, and $35 \mathrm{~km}$. The horizontal and vertical dashed lines indicate the maximum depth and range recorded by the satellite tag during this dive, respectively. Figures 8(b) and 8(c) to 10(b) and 10(c) show the corresponding ambiguity surfaces created using the WMS and NMS methods described in Sec. III B 3. For both methods, the location uncertainty grows with range, a point discussed further in the following text. Ways to reduce these uncertainties are discussed in Sec. VI.

\section{Sources of localization error}

The sensitivity of the localization procedures to various sources of bias were examined, including inclination bias, sound speed bias, and uncertainties on measuring relative arrival times and elevation angles. All sensitivity studies simulated a source at $400 \mathrm{~m}$ depth and $10 \mathrm{~km}$ range.

The standard deviation of the measured array inclination was $0.3^{\circ}$. A $1^{\circ}$ inclination (or three times that of the measured inclinometer uncertainty) translated into a $5.5 \%$ underestimate in range. In general, the addition of a $20 \mathrm{~kg}$ lead sphere underneath the vertical array seemed successful in keeping the array inclination nearly vertical. Adding a $5 \mathrm{~m} / \mathrm{s}$ a) August 15th 2010 - 19:50:33

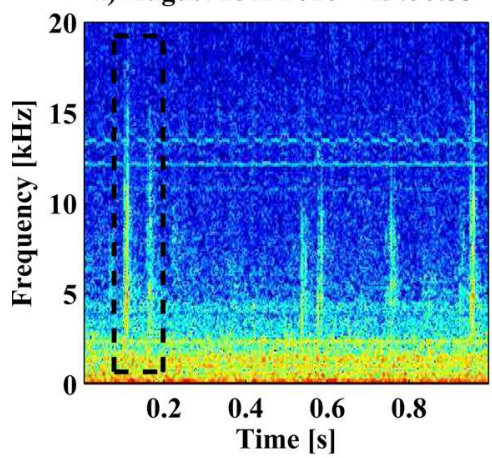

c) August 16th $2010-12: 15: 34$

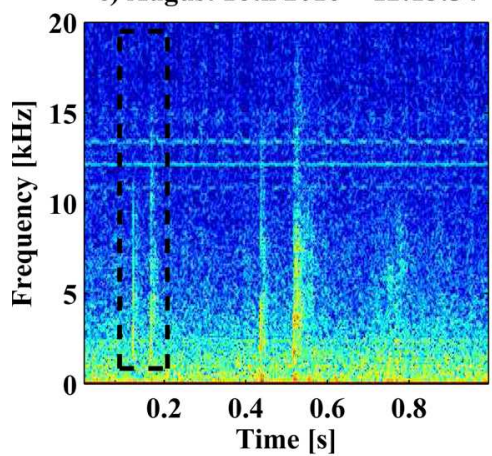

b) August 16th 2010 - 13:49:03
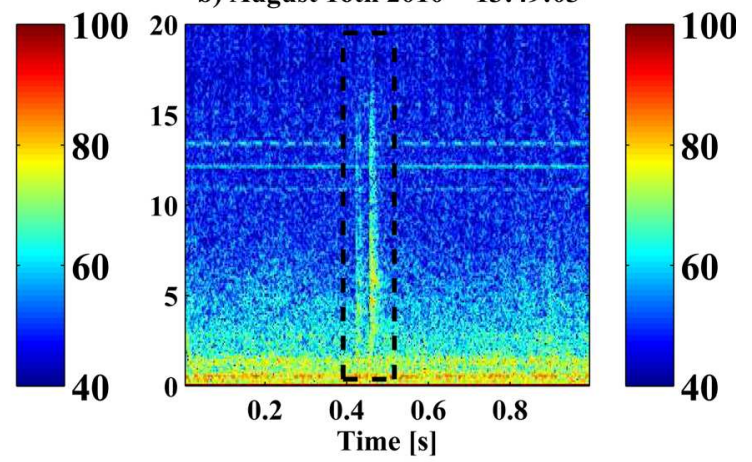

d) August 16th 2010 - 19:10:17

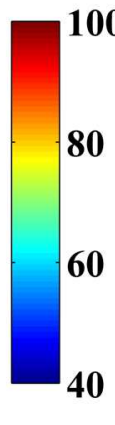

80

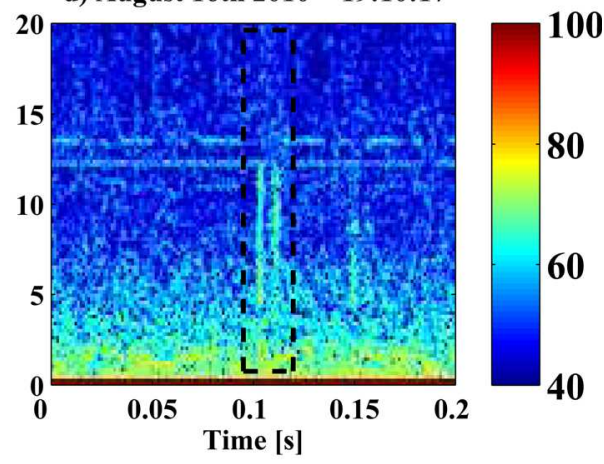

FIG. 7. (Color online) Spectrograms of the ray path arrivals (dashed box) used for localization when the whale range was (a) $2 \mathrm{~km}$, (b) $5 \mathrm{~km}$, (c) $8 \mathrm{~km}$, (d) $22 \mathrm{~km}$, and (e) $35 \mathrm{~km}$ from the vertical array. The scale corresponds to the power spectral density in units of $\mathrm{dB}$ re $1 \mu \mathrm{Pa}^{2} / \mathrm{Hz}$.

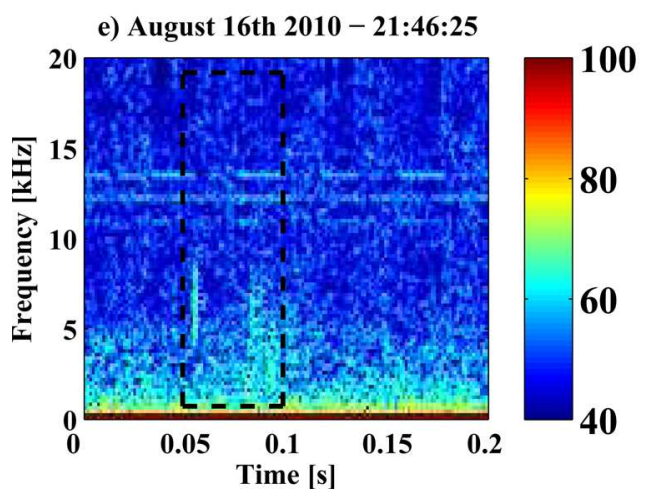


a) Ambiguity Surface - Scoring method - 16 August 2010 - 13:49

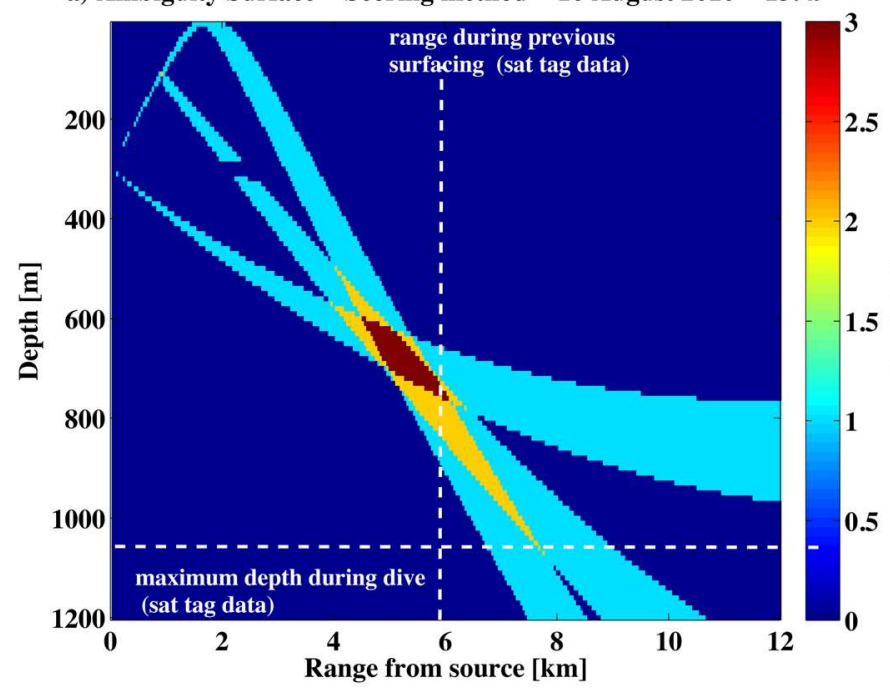

c) Ambiguity Surface - NMS - 16 August 2010 - 13:49

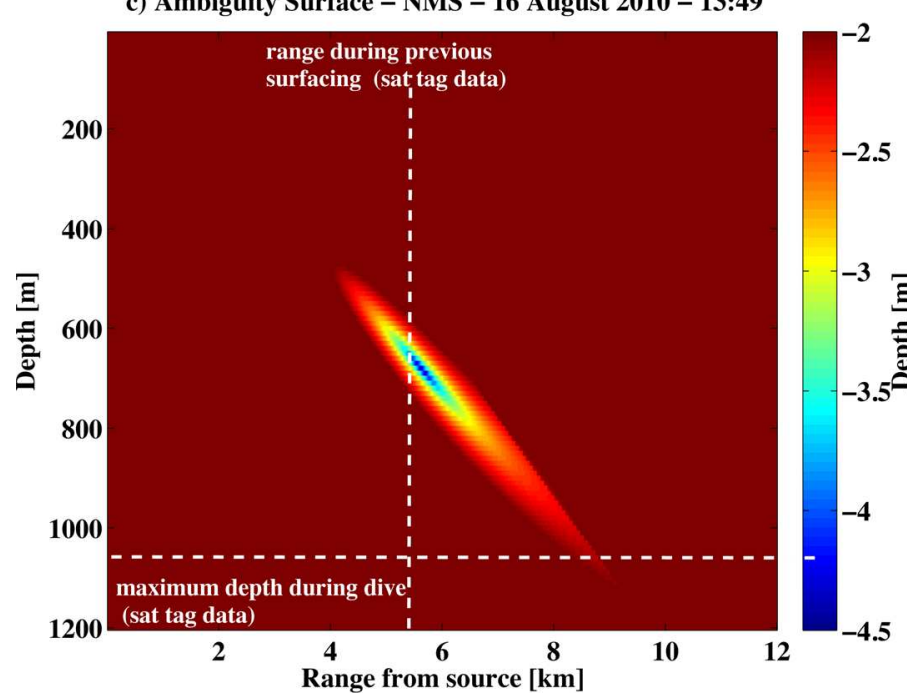

b) Ambiguity Surface - WMS - 16 August 2010 - 13:49

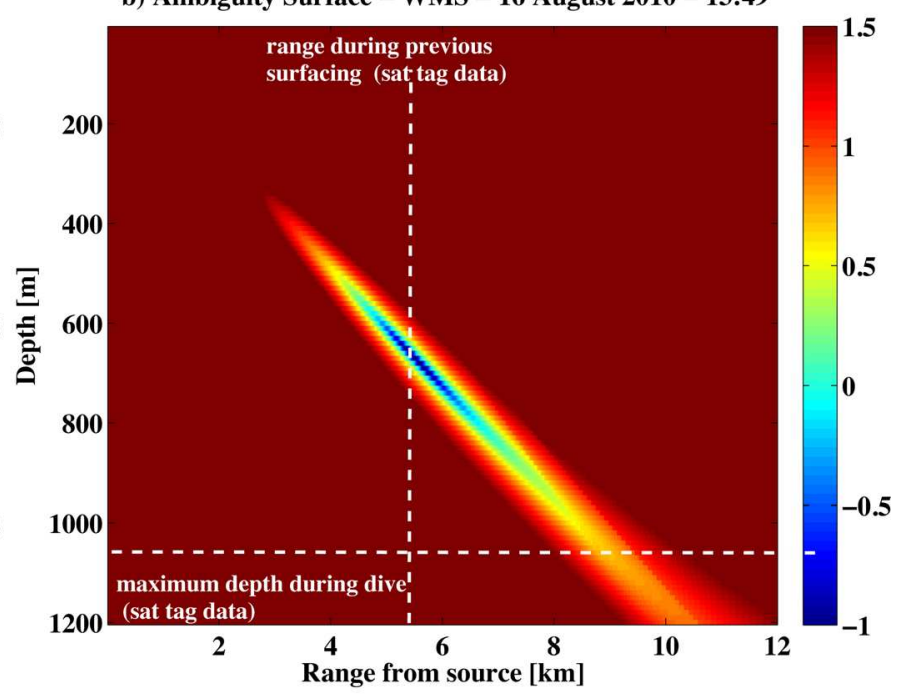

d) Bellhop - Eigenrays at $5 \mathrm{~km}$ range

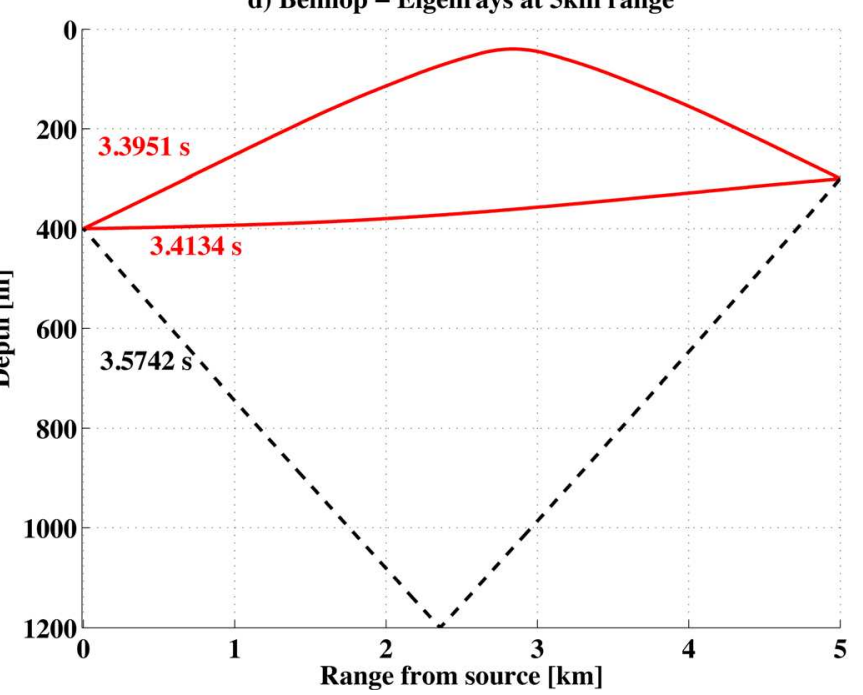

FIG. 8. (Color online) Localization estimates of satellite-tagged whale at $5 \mathrm{~km}$ range. The horizontal and vertical dashed lines indicate the maximum depth and range recorded by the satellite tag during this dive. (a) Ambiguity surfaces using scoring method (Sec. III B 2) on data shown in Fig. 7(b). High scores indicate likely source positions. (b) Ambiguity surfaces using weighted mean-square (WMS) error method. The error term for each measurement variable is weighted equally (Sec. III B 3), and a logarithmic scale is used. Low values indicate likely source positions. (c) Ambiguity surfaces using normalized meansquare (NMS) error. (d) Eigenrays and travel times modeled between a sperm whale at $400 \mathrm{~m}$ depth and a hydrophone at $300 \mathrm{~m}$ depth and $5 \mathrm{~km}$ range. Solid lines represent direct and refracted paths. The dashed line indicates a path that is predicted in the model but was not found in the vertical array data. Travel times (in seconds) are indicated for the paths described in the preceding text.

bias to the sound speed profile of Fig. 3(b) resulted in a $1.5 \%$ underestimate in range. By contrast, the sound speed profile at the deployment depth changed by only $0.1 \mathrm{~m} / \mathrm{s}$ during the deployment. The estimated standard deviation of the relative arrival time and elevation angle estimate were $5 \mathrm{~ms}$ and $1^{\circ}$, respectively. When these uncertainties were added as biases to the simulated arrival data, the ranges were underestimated by $3.5 \%$ and $5 \%$, respectively.

Thus the expected localization error arising from measured array tilt and arrival angles were roughly equal and were greater than errors arising from the measurement of click arrival times and sound speed. However, all location errors were within $5 \%$ of the true range.

The issue of potential "sidelobes" in the tracking method was also investigated. At ranges greater than $25 \mathrm{~km}$ two disjoint regions emerge as possible whale locations in Figs. 10(a)-10(c): One at roughly $28 \mathrm{~km}$ and one at $35 \mathrm{~km}$. The emergence of this ambiguous estimate is explained by the eigenray travel times and arrival angles shown in Fig. 9(d). At this range, two trapped ray paths arrive at $35 \mathrm{~km}$ with similar vertical elevation angles and slightly different travel times (the dash-dot line shows the sidelobe's eigenray path). It is this difference in travel time that splits the candidate locations into two distinct patches. The WMS method and NMS methods [Figs. 10(b) and $10(\mathrm{c})$ ] seem to be able to break the ambiguity, while the scoring method does not [Fig. 10(a)]. As discussed in Sec. V A, at large ranges several eigenrays can have similar travel times; thus for a finite-duration source signal they would be merged together in the received data, making it difficult to identify the individual ray paths illustrated in Fig. 7(e). 
a) Ambiguity Surface - Scoring method - 16 August 2010 - 19:10

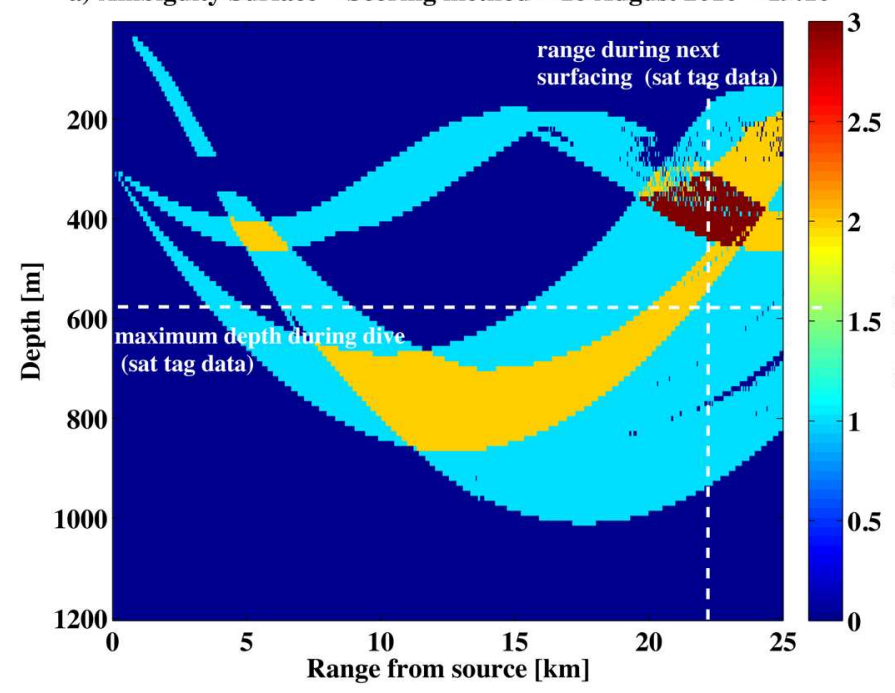

c) Ambiguity Surface - NMS - 16 August 2010 - 19:10

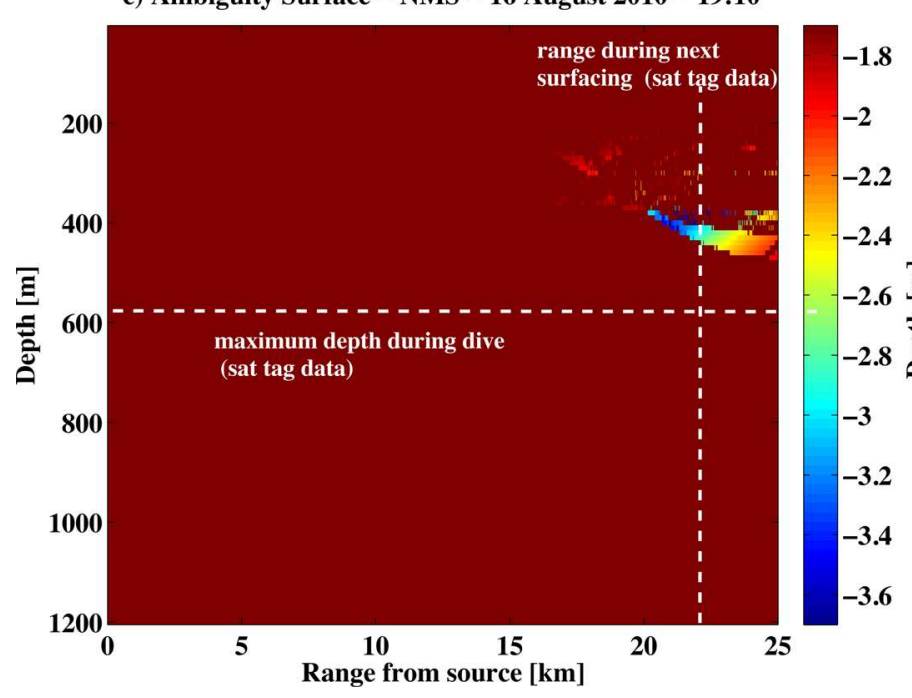

b) Ambiguity Surface - WMS - 16 August 2010 - 19:10

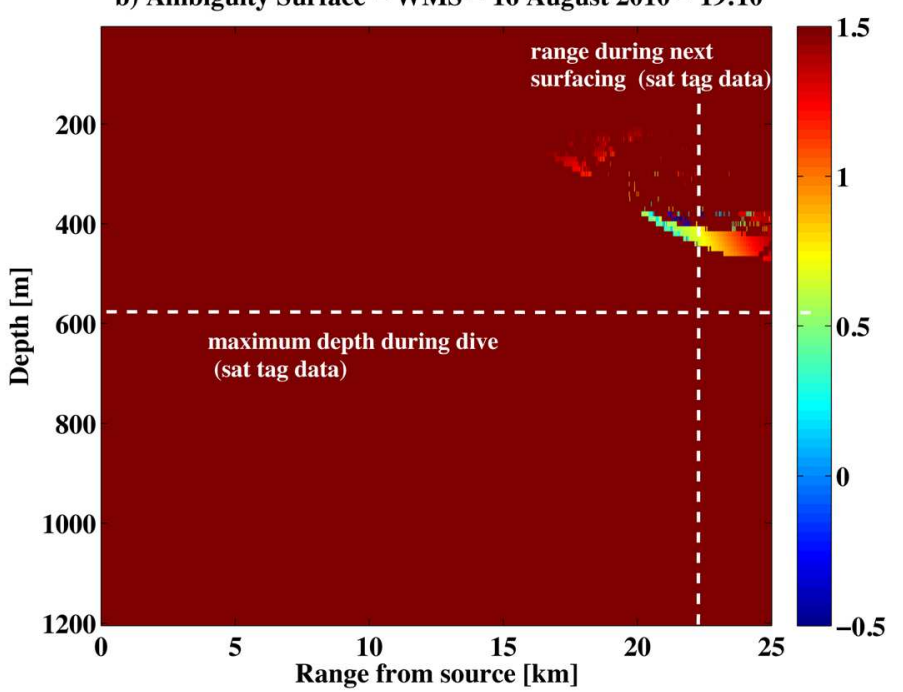

d) Bellhop - Eigenrays at $20 \mathrm{~km}$ range

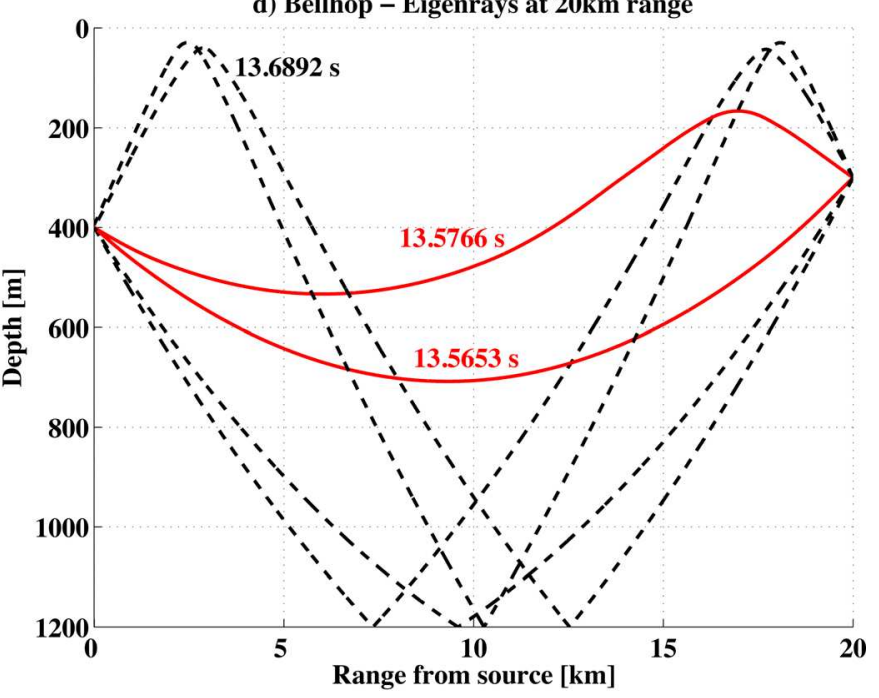

FIG. 9. (Color online) Similar to Fig. 8, but for multipath arrivals recorded on the vertical array on 16 August 2010 at 19:10 [Fig. 7(c)]. The source depth in subplot (d) was modeled at $400 \mathrm{~m}$ depth.

\section{B. Interpreting acoustic propagation effects at various ranges}

To gain insight into the basic transmission loss properties of the region, the acoustic propagation model BELLHOP was used to predict the acoustic ray path travel times, arrival angles and transmission loss between a hypothesized sperm whale at $400 \mathrm{~m}$ depth and a hydrophone at $300 \mathrm{~m}$ depth at various ranges. The simplest analytical transmission loss model that best fit the transmission losses computed by BELLHOP as a function of range was $17 \log R$, plus Thorp attenuation at 3 or $6 \mathrm{kHz}$ (Thorp, 1967), depending on the center frequency of the received bandwidth. Sections IV C and $\mathrm{VC}$ will use this result extensively when estimating sperm whale source levels and maximum detection range.

Figures 8(d)-10(d) display examples the eigenrays modeled between the localized sperm whale depths and the 300 $\mathrm{m}$ deep hydrophone at 5, 22, and $35 \mathrm{~km}$ ranges, along with their associated travel times. Only paths with one interface reflection or less are shown. Up to a $2 \mathrm{~km}$ range, the eigenrays between the source and the receiver can be easily labeled as direct, surface-reflected, and bottom-reflected paths. At the $2 \mathrm{~km}$ range, the assumption of straight ray propagation seems valid; this explains why the analytic formulas worked well up to that range.

By the $5 \mathrm{~km}$ range, the surface-reflected path has transformed into a refracted path that does not contact the surface [Fig. 8(d)]. The surface-refracted path arrives before the direct path as the sound speed is greater closer to the surface.

By the $35 \mathrm{~km}$ range, seven distinct refracted eigenrays appeared, all arising from being trapped in the minimum sound speed channel. Interestingly, only two ray arrivals were confidently extracted at long ranges [Fig. 7(e)]. Our initial explanation for this discrepancy is that many of the modeled eigenrays have arrival times within $20 \mathrm{~ms}$ of each other, so additional ray paths might have been recorded by the vertical array but could not be separated in time as sperm whale click durations are on the order of $10 \mathrm{~ms}$. To investigate this hypothesis, Fig. 11 displays the duration, maximum frequency, and bandwidth of the two ray paths used for 
a) Ambiguity Surface - Scoring method - 16 August 2010 - 21:46

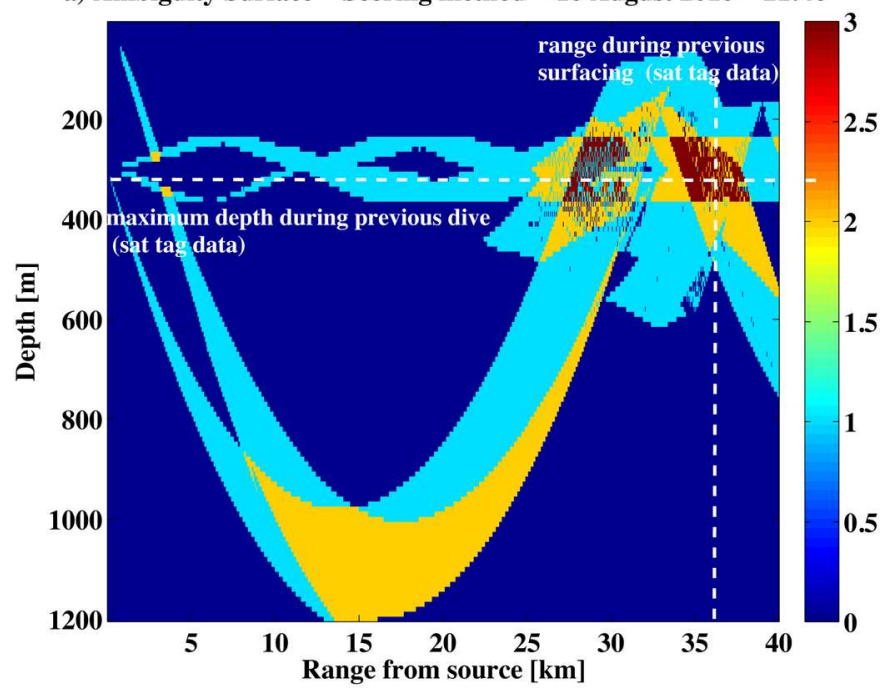

c) Ambiguity Surface - NMS - August 16th 2010 - 21:46

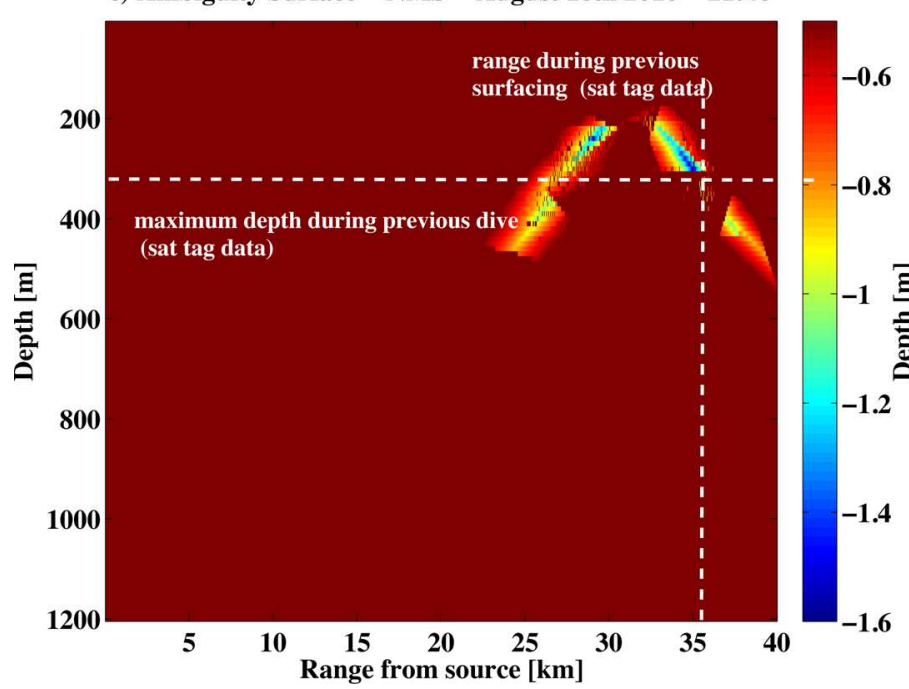

b) Ambiguity Surface - WMS - 16 August 2010 - 21:46

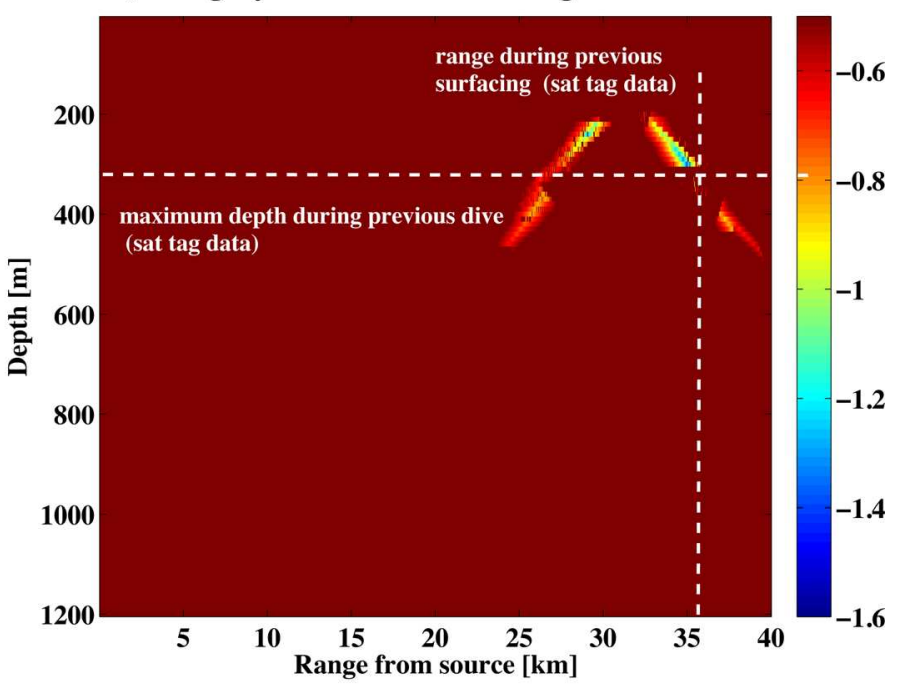

d) Bellhop - Eigenrays at $35 \mathrm{~km}$ range

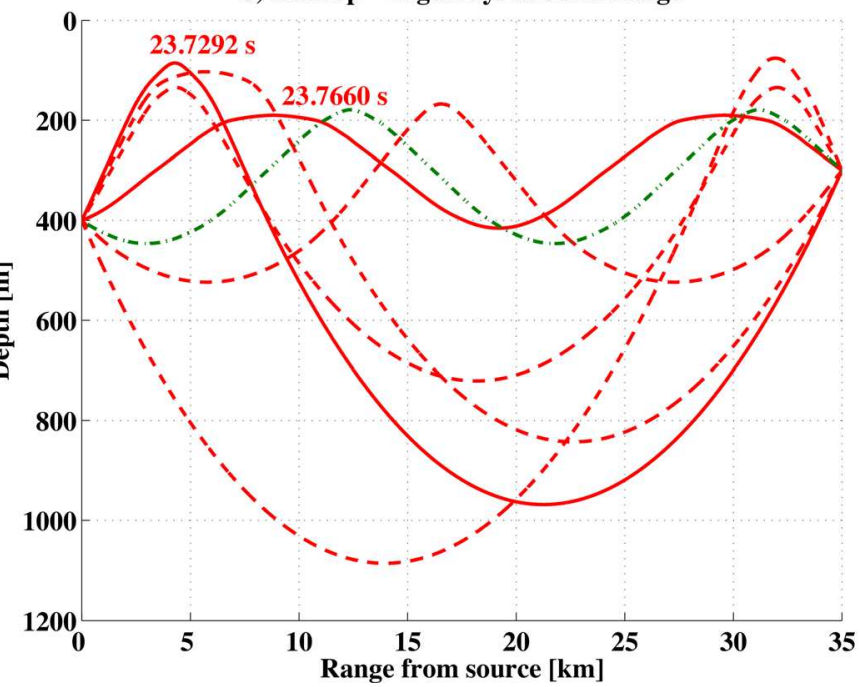

FIG. 10. (Color online) Similar to Fig. 8, but for multipath arrivals recorded on the vertical array on 16 August 2010 at $21: 46$ [Fig. 7(e)]. In subplot (d), the source depth was modeled at $400 \mathrm{~m}$ depth. The dash-dot line indicates a path that is predicted in the model that generates a sidelobe in the ambiguity surface.

localization a between 2 and $35 \mathrm{~km}$ range (as seen in the spectrograms in Fig. 7). The duration of each pulse was computed according to the cumulative SEL method described in Sec. IIIC The plots show that the ray arrivals' duration lengthens with increasing source range with the secondary ray path (associated with the path trapped in the sound speed minimum channel) displaying a longer duration than the primary path at higher ranges.

One might argue that this pulse lengthening arises primarily from the reduction in signal bandwidth that in turn arises from the attenuation of the high frequency components at greater ranges as indicated by the bottom subplot in Fig. 11. However, the duration of the primary path's pulse is similar at the 22 and $35 \mathrm{~km}$ range, but over the same range interval, the secondary path's pulse duration nearly doubles, even though the bandwidths of both arrivals decrease in the same manner over the same range interval. This difference in duration suggests that a simple volume attenuation of higher frequency components with range is insufficient for explaining the increase in pulse duration for the trapped refracted ray path, and thus the presence of several closely arriving ray paths cannot be discounted.

\section{Source level estimates}

\section{Click source levels}

The combined acoustic and tagging data, along with the BELLHOP-derived transmission loss, were used to estimate the tagged sperm whale's click source levels over the detected bandwidth. Received levels (RL) for clicks emitted at known ranges were estimated using the three different metrics defined in Sec. III C.

The acoustic source levels were derived by adding the estimated transmission loss from the previous subsection to the received levels out to a $35 \mathrm{~km}$ range using the sonar equation (Urick, 1983)

$$
S L=R L+T L
$$



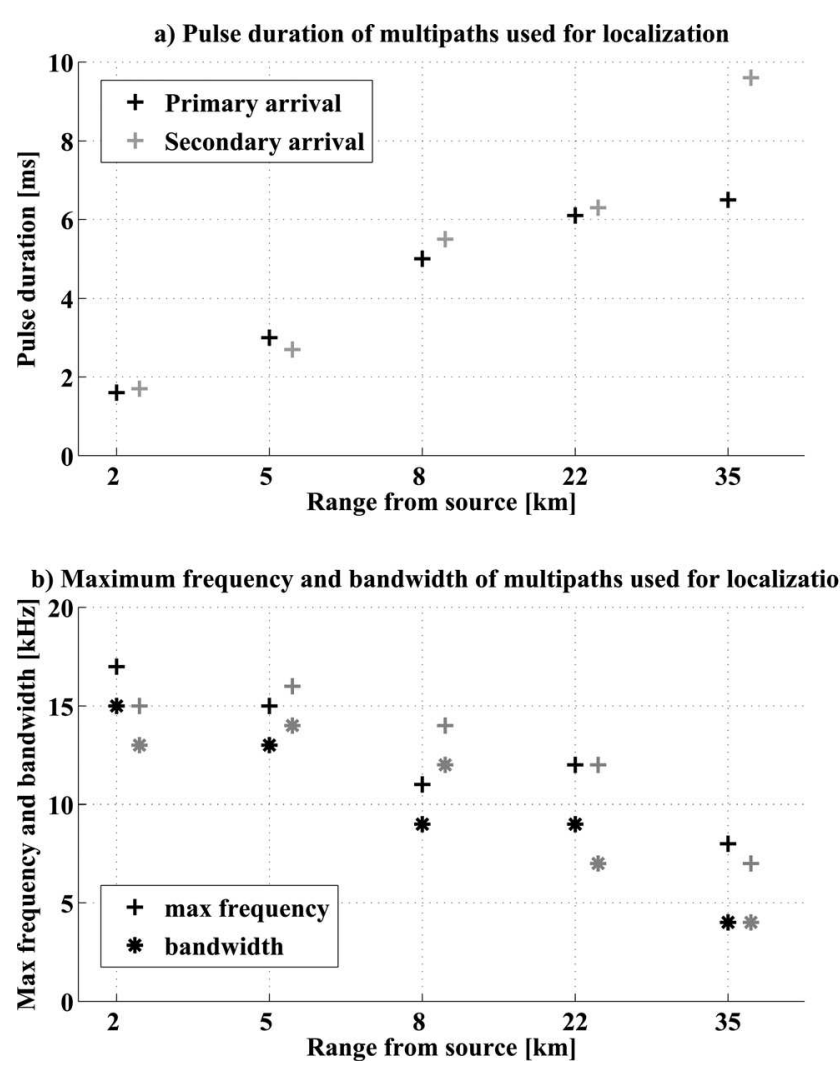

FIG. 11. (a) Duration in ms of the ray path arrivals used for localization. The duration was computed by taking the part of the waveform that made up $90 \%$ of the cumulative equalized SEL values in the time series (Sec. IV B). The black symbols indicate the first multipath arrival, and the gray symbols indicate the second multipath arrival. (b) Maximum frequency (cross) and bandwidth (star) in kilohertz of the ray arrivals.

where $S L$ is source level, $R L$ is received level, and $T L$ is transmission loss all in decibel units. Equation (4) was evaluated using the three received level metrics (peak-to-peak, rms, and SEL), the $17 \log (R)$ transmission loss approximation from the BELLHOP model, and Thorp volume attenuation. The results show that the tagged sperm whale's source level remains consistent over time in terms of rms received level and SEL: $186( \pm 0.9) \mathrm{dB}$ re $1 \mu \mathrm{Pa} @ 1 \mathrm{~m}(\mathrm{rms})$, and $170( \pm 0.7) \mathrm{dB}$ re $1 \mu \mathrm{Pa}^{2}$-s @ $1 \mathrm{~m}$ (SEL). The peak-to-peak source level varies between 200 and 205 dB re $1 \mu \mathrm{Pa} @$ $1 \mathrm{~m}(\mathrm{pp})$.

\section{Creak click source levels}

Sperm whales occasionally produce "creak" (or "buzz") sounds, a sequence of clicks produced at a rate of 10 per second or faster (Gordon, 1987; Madsen et al., 2002) and often characterized by a decrease in the amplitude over the 5- to 30-s duration of the sound (Whitehead and Weilgart, 1991; Whitehead, 2003). Madsen et al. (2002) reported creak source levels (using five recorded creaks) between 179 and $205 \mathrm{~dB}$ re $1 \mu \mathrm{Pa}(\mathrm{rms})$, levels that are about $20 \mathrm{~dB}$ smaller than usual click source levels. A reduced source level has also been seen observed in echolocation buzzes of harbor porpoises (DeRuiter et al., 2009).

Here creak source levels were estimated using creaks produced by the tagged whale at close ranges to the vertical array when the B-probe was attached. The acoustic data from the B-probe were first manually reviewed to detect creak events, and a total of 20 creaks was found during the three dives recorded by the B-probe. The vertical array data were then manually reviewed to find the creaks produced by the tagged whale. Ten of the tagged whale's creaks were identified in the vertical array data, demonstrating that creaks could be detected up to at least a $1.6 \mathrm{~km}$ range under sea state 3 conditions.

Received levels of clicks within these ten creaks were $134 \pm 6 \mathrm{~dB}$ re $1 \mu \mathrm{Pa}(\mathrm{pp})$ and between $125 \pm 5 \mathrm{~dB}$ re $1 \mu \mathrm{Pa}$ (rms). The high directionality of creak clicks may explain the large dynamic range in received level (Madsen et al., 2002) as the received levels would fade in and out as the whale changes its orientation relative to the vertical array. Corresponding source levels were estimated using the spherical transmission loss model because the whale was very close to the vertical array, yielding source levels of $180 \pm 6$ $\mathrm{dB}$ re $1 \mu \mathrm{Pa} @ 1 \mathrm{~m}(\mathrm{pp})$ and $171 \pm 5 \mathrm{~dB}$ re $1 \mu \mathrm{Pa} @ 1 \mathrm{~m}$ (rms). These source levels are about $20 \mathrm{~dB}$ lower than usual click source levels measured in the previous subsection, consistent with the pattern observed by Madsen et al. (2002).

\section{DISCUSSION}

\section{A. Comparison of ambiguity surface construction methods}

The "scoring method" described in Sec. III B 2 is robust when using both time difference of arrival and arrival angle values as it does not require any unit normalization. However, the scoring method has a poor precision. Indeed the range uncertainty is already $1.8 \mathrm{~km}$ for a source at a $5 \mathrm{~km}$ range [Fig. 8(a)], and the scoring method cannot distinguish between the sidelobes at a $35 \mathrm{~km}$ range [Fig. 10(a)].

The advantage of the "weighted mean-square error" (WMS) and "normalized mean-square error" (NMS) approaches over the "scoring method" is the localization precision: The range uncertainty is $0.5 \mathrm{~km}$ for a source at the $5 \mathrm{~km}$ range [Figs. 8(b) and 8(c)]; this is even smaller than the average ARGOS location uncertainty of $\sim 1.5 \mathrm{~km}$. At a $22 \mathrm{~km}$ range, the range uncertainty is $2 \mathrm{~km}$ for the WMS method and $1 \mathrm{~km}$ for the NMS error [Figs. 9(b) and 9(c)]. Both the WMS and NMS methods also resolve the sidelobe ambiguity at $35 \mathrm{~km}$ [Figs. 10(b) and 10(c)], but the NMS method provides a more precise localization with a range uncertainty of only $1 \mathrm{~km}$, similar to the ARGOS location uncertainty.

\section{B. Consistency in source levels of tagged whale}

The fact that the source level remains so steady over days is somewhat surprising at first because sperm whale clicks have been demonstrated to be highly directional (Møhl et al., 2003; Zimmer et al., 2005), so one might expect to see some source level variation with range because it is unlikely that the sperm whale remains at the same relative orientation to the hydrophone at the start of every dive. Zimmer et al. (2005) provides one possible explanation in that the paper showed that sperm whale clicks are composed of three components: An omnidirectional low-frequency 
(LF) component with energy below $3 \mathrm{kHz}$, a highly directional and forward-directed component P1 with energy above $3 \mathrm{kHz}$ and a low directionality component $\mathrm{P} 0$ pointing backward with energy above $3 \mathrm{kHz}$. The LF component would be expected to dominate at long range as the peak frequency of the detected clicks decreases with increasing range. The fact that only the $\mathrm{P} 0$ and LF portions of the click are being detected at long ranges could also explain why the apparent source level estimates in this study are lower than the $235 \mathrm{~dB}$ re $1 \mu \mathrm{Pa}$ (pp) source level reported by Møhl et al. (2000). He also reported a centroid frequency of $15 \mathrm{kHz}$, suggesting that he was measuring the P1 source level.

Caution should be used when using sperm whale source levels estimated from short-range measurements to estimate the ultimate detection range of sperm whales with passive acoustic equipment in that the detection ranges can be overestimated. The "apparent source levels" reported here are probably a more reliable guide for modeling sperm whale detection ranges in North Pacific waters.

\section{Limits of detection and tracking range as a function of sea state}

In previous sections, the source levels of sperm whales have been estimated, and the transmission loss characteristics of the environment have been obtained as a byproduct of the localization procedure. We use this information to estimate the ultimate detection and tracking ranges of the vertical array system as a function of sea state to help provide guidelines for designing future experiments for passive acoustic monitoring of sperm whales in similar environments. Results like these are essential in assisting estimates of sperm whale density using acoustics (Barlow and Taylor, 2005). Here the "detection range" of a sperm whale is defined as a range where at least one ray path would be predicted to have a $2 \mathrm{~dB}$ signal-to-noise ratio in terms of power spectral density (PSD). This threshold was chosen while manually reviewing spectrograms, where it was found that a $2 \mathrm{~dB}$ SNR was needed to visually detect a click arrival. The "tracking range" is defined as a range where at least two distinct ray paths would have more than $2 \mathrm{~dB}$ SNR. A difference of as much as $5 \mathrm{~dB}$ can exist between the received levels of two ray arrivals (Fig. 7), and thus the tracking range would be expected to be less than the detection range.

The sonar equation states that a sperm whale click will be detected if the signal-to-noise ratio (SNR) exceeds a detection threshold (DT). In this study, the DT is assumed to be $2 \mathrm{~dB}$, and the SNR at the receiver becomes

$$
S N R=S L-T L-A N L,
$$

where $S L$ is the click source level: $186 \mathrm{~dB}$ re $1 \mu \mathrm{Pa}$ (rms) (Sec. IV C 1), TL is $17 \log (R)$, plus Thorp attenuation, and $A N L$ is the rms ambient noise level measured over the same bandwidth of the click.

The ambient noise levels measured during the 2-day experiment were estimated as follows. First, a set of PSD spectra was computed over the $0.2-24 \mathrm{kHz}$ frequency range using a 1024 point FFT size with $50 \%$ overlap, then all PSD spectra over a $0.5 \mathrm{~s}$ interval were averaged. This relatively short time interval was chosen to increase the odds that a sperm whale click would not be incorporated into the average because the click interval of a single sperm whale is generally greater than $0.5 \mathrm{~s}$. The ambient noise level was then calculated by taking the minimum value of the summed pressure spectral density over the $2-10 \mathrm{kHz}$ frequency band every $4 \mathrm{~s}$ (Guerra et al., 2011). By taking the minimum, PSD samples contaminated by sperm whale click spectra could be rejected. The occasional increase in noise level arose from vessel noise from the F/V Northwest Explorer, but the ambient noise level over the sperm whale $2-10 \mathrm{kHz}$ click bandwidth held relatively consistent at $95 \mathrm{~dB}$ re $1 \mu \mathrm{Pa}$ (rms).

The Beaufort sea state was estimated to be 3 during the 2-day experiment with wind speeds of 3-6 m/s logged by the NOAA Fairweather buoy (http://www.ndbc.noaa.gov/). The average value of the pressure spectral density at $2 \mathrm{kHz}$ is 58 $\mathrm{dB}$ re $1 \mu \mathrm{Pa}^{2} / \mathrm{Hz}$, which matches well the $60 \mathrm{~dB}$ re $1 \mu \mathrm{Pa}^{2} / \mathrm{Hz}$ noise level predicted by (Wenz, 1962) at the same frequency and sea state.

Ambient noise levels were then modeled for Beaufort sea states ranging from 0 to 5, and Eq. (5) was used to derive sperm whale detection and tracking ranges as a function of sea state, using a manual-review detection threshold of $2 \mathrm{~dB}$ (Fig. 12). The detection range is predicted to be up to $90 \mathrm{~km}$ in calm sea conditions and up to $35 \mathrm{~km}$ in high wind conditions of $12 \mathrm{~m} / \mathrm{s}$. The tracking range is predicted to be up to $75 \mathrm{~km}$ in calm sea conditions and up to $19 \mathrm{~km}$ in high wind conditions. The sonar equation predicts that for a sea state of 3 , the tracking range would be $42 \mathrm{~km}$, and indeed in this study, we were able to track a sperm whale in an up to $35 \mathrm{~km}$ range (Sec. IV A 2). The figure can be adjusted for creak detection level by reducing the modeled source levels by 15 $\mathrm{dB}$, reducing the detection ranges shown in Fig. 12 by a factor of 7 . Thus at sea state 3 conditions, the predicted detection range for creaks is $5 \mathrm{~km}$. In this experiment, detection ranges of at least $1.6 \mathrm{~km}$ at sea state 3 were confirmed, but

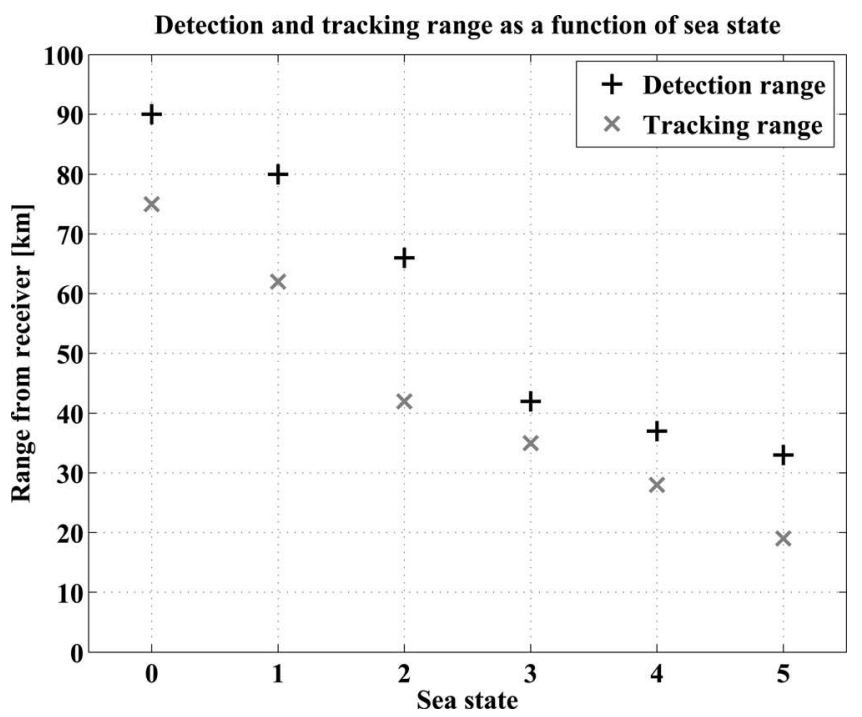

FIG. 12. Estimated detection and tracking range of usual sperm whale clicks by vertical array system as a function of sea state, using a detection threshold of $2 \mathrm{~dB}$. Detection range of creaks can be estimated by dividing detection ranges by 7 . 
the upper limit could not be verified due to lack of B-probe data at greater ranges.

\section{CONCLUSION}

This paper has reviewed the sperm whale detection and tracking performance of a simple two-element vertical array placed at the depth of the sound speed minimum in highlatitude waters. Tagging data were used to validate the accuracy of passive acoustic tracking techniques that used both analytic and numeric sound propagation models. The results show that beyond a $2 \mathrm{~km}$ range, it is necessary to use an accurate sound speed profile and a numerical propagation model to account for ray-refraction effects. After modeling arrival times and arrival angles of ray paths with BELLHOP, several methods were used to construct ambiguity surfaces. The NMS resulted in a better accuracy than the WMS and the scoring methods. However, one potential disadvantage of the NMS method is that the weighting terms are influenced by the set of source locations chosen for modeling, a concern that seems to have little practical impact. Using the NMS method, the tagged whale was tracked in an up to $35 \mathrm{~km}$ range under sea state 3 conditions with a $\pm 1 \mathrm{~km}$ range uncertainty that matches the uncertainty of the satellite location measurements. One substantial advantage of all the techniques described here is that no independent knowledge of the local bathymetry is required because ray paths that interact with the ocean bottom are rejected from the analysis. Bottom-interacting paths generally produce distinctive changes to the detected signal that can be recognized during the analysis.

The data collected during the 2-day vertical array deployment also permitted modeling of the propagation environment, and the best simple analytical fit to the BELLHOP transmission loss curve was found to be $17 \log (\mathrm{R})$, plus Thorp attenuation. These transmission losses were used to estimate the apparent sperm whale's click source level at 186 $\mathrm{dB}$ re $1 \mu \mathrm{Pa}$ (rms), a value that varied little over time and source range and is lower than previously reported source level measurements conducted at much shorter ranges. All this information, combined with the ambient noise statistics gathered from the deployment, suggest that even under sea state 5 conditions, sperm whale detection ranges are possible up to $35 \mathrm{~km}$ with tracking ranges up to $19 \mathrm{~km}$.

However, as discussed in Secs. IV A 3 and V, localization uncertainty increased with range, and an ambiguity surface can even display multiple possible whale locations several kilometers apart from each other. Further work is thus required to improve the uncertainty at longer ranges.

We only used clicks emitted during the initial descent of the whale for localization. Using clicks from the entire dive profile could improve the localization estimates by exploiting the depth diversity of all the ray paths and using the fact that the range estimate should change relatively little during the entire dive. This approach would require the ability to extract clicks from the "target whale" when other whales are vocalizing simultaneously. This tracking technique might also be viable at lower-latitude locations with the caveat that the foraging depths of sperm whale may no longer match the (deeper) location of the sound speed minimum, which may lead to shadow zones (ranges of no detection) of passive acoustic gear deployed at only one depth.

Finally, this technique might be used to flag simple "rules of thumb" for estimating ranges in single-hydrophone recordings. For example, we have shown how the duration and bandwidth of the various multipath component of the sperm whale signal are closely related to the measured range. Thus a possibility exists that a single vertical array deployment could be used to "calibrate" the detection ranges of multiple other single-channel acoustic recorders deployed in the same region.

\section{ACKNOWLEDGMENTS}

The authors thank the captain and crew of the F/V Northwest Explorer and NOAA AFSC Auke Bay Laboratory at Ted Stevens Marine Research Institute, Juneau, AK; in particular the authors thank Chris Lunsford and Phil Rigby for the use of the vessel providing the mechanism for buying satellite tags. Improvements to the LIMPET satellite tagging system were funded by the Office of Naval Research. We also thank John Moran for assisting with the fieldwork and representing NOAA oversight on the F/V Northwest Explorer. Without John's perseverance, the bioacoustics tag would not have been deployed. Visual identification using photographs of dorsal fins and flukes of unique sperm whales was possible thanks to Jen Cedarleaf, Ellen Chenoweth, and Lauren Wild of the University of Alaska Southeast and the Sitka Sound Science Center. Michael Porter provided useful guidance on running BELLHOP over large ranges. Research was approved by University of Alaska IACUC and NOAA OPR Permit NO. 14122. Delphine Mathias was supported by the North Pacific Research Board Graduate Student Research Award and NOAA.

Andrews, R. D., Pitman, R. L., and Balance, L. T. (2008). "Satellite tracking reveals distinct movement patterns for Type B and Type $\mathrm{C}$ killer whales in the southern Ross Sea," Polar Biol. 31, 1461-1468.

Antonov, J. I., Seidov, D., Boyer, T. P., Locarnini, R. A., Mishonov, A. V., Garcia, H. E., Baranova, O. K., Zweng, M. M., and Johnson D. R. (2010). "World Ocean Atlas 2009, Salinity," in NOAA Atlas NESDIS 69, edited by S. Levitus (U.S. Government Printing Office, Washington, DC), Vol. 2, 184 pp.

Baggenstoss, P. M. (2011). "Separation of sperm whale click-trains for multipath rejection," J. Acoust. Soc. Am. 129(6), 3598-3609.

Barlow, J., and Taylor, B. L. (2005). "Estimates of sperm whale abundance in the northeastern temperate Pacific from a combined acoustic and visual survey," Mar. Mamm. Sci. 21, 429-445.

Burgess, W. C., Tyack, P. L., Le Boeuf, B. J., and Costa, D. P. (1998). “A programmable acoustic recording tag and first results from free-ranging northern elephant seals," Deep-Sea Res., Part II 45(7), 1327-1351.

Costa, D. P., Robinson, P. W., Arnould, J. P. Y., Harrison, A.-L, Simmons, S. E., Hassrick, J. L., Hoskins, A. J., Kirkman, S. P. Oosthulzen, H., Villegas-Amtmann, S., and Crocker, D. E. (2010). "Accuracy of ARGos locations of pinnipeds at-sea estimated using Fastloc GPS," PLoS ONE 5(1), e8677.

DeRuiter, S. L., Bahr, A., Blanchet, M.-A., Hansen, S. F., Kristensen, J. H., Madsen, P. T., Tyack, P. L., and Wahlberg., M. (2009). "Acoustic behaviour of echolocating porpoises during prey capture,” J. Exp. Biol. 212, 3100-3107.

Goldbogen, J. A., Calambokidis, J., Shadwick, R. E., Oleson, E., McDonald, M., and Hildebrand, J. A. (2006). "Kinematics of foraging dives and lunge-feeding in fin whales," J. Exp. Biol. 209, 1231-1244. 
Gordon, J. C. D. (1987). "Sperm whale groups and social behaviour observed off Sri-Lanka,” Rep. Int. Whal. Commun. 37, 205-217.

Guerra, M., Thode, A., Blackwell, S., and Macrander, M. (2011). "Quantifying seismic survey reverberation off the Alaskan North Slope," J. Acoust. Soc. Am. 130(5), 3046-3058.

Hanselman, D. H., Fujioka, J. T., Lunsford, C. R., and Rodgveller, C. J. (2009). "Assessment of sable fish stock in Alaska," in Stock Assessment and Fishery Evaluation Report for Ground Fish Resources of the Gulf of Alaska, (Alaska Fisheries Science Center National Marine Fisheries Service, Seattle, WA), pp. 353-464.

Leaper, R., Chappell, O., and Gordon, J. (1992). "The development of practical techniques or surveying sperm whale populations acoustically," Rep. Int. Whal. Commun. 42, 549-560.

Mackenzie, K. V. (1981). "Nine-term equation for the sound speed in the oceans," J. Acoust. Soc. Am. 70(3), 807-812.

Madsen, P. T. (2005). "Marine mammals and noise: Problems with root mean square sound pressure levels for transients," J. Acoust. Soc. Am. 117(6), 3952-3957.

Madsen, P. T., Wahlberg, M., and Møhl, B. (2002). "Male sperm whale (Physeter macrocephalus) acoustics in a high latitude habitat: Implications for echolocation and communication," Behav. Ecol. Sociobiol. 53, 31-41.

Malme, C. I., Smith, P. W., and Miles, P. R. (1986). "Characterisation of geophysical acoustic survey sounds," OCS Study. Prepared by BBN Laboratories Inc., Cambridge, for Battelle Memorial Institute to the Department of the Interior-Mineral Management Service, Pacific Outer Continental Shelf Region, Los Angeles, CA.

Mathias, D., Thode, A., Straley, J., and Folkert, K. (2009). "Relationship between sperm whale (Physeter macrocephalus) click structure and size derived from video camera images of a depredating whale," J. Acoust. Soc. Am. 125(5), 3444-3453.

Mathias, D., Thode, A., Straley, J., O'Connell, V., Calambokidis, J., and Schorr, G. S. (2012). "Acoustic and foraging behavior of tagged sperm whales (Physeter Macrocephalus) under natural and depredation foraging conditions in the Gulf of Alaska," J. Acoust. Soc. Am. 132(1), 518-532.

McDonald, M. A., Hildebrand, J. A., and Webb, S. C. (1995). "Blue and fin whales observed on a seafloor array in the Northeast Pacific," J. Acoust. Soc. Am. 98, 712-721.

Mellinger, D. K., Stafford, K. M., and Fox, C. G. (2004). "Seasonal occurrence of sperm whale (Physeter macrocephalus) sounds in the Gulf of Alaska, 1999-2001," Mar. Mamm. Sci. 20(1), 48-62.

Møhl, B., Wahlberg, M., Madsen, P. T., Heerfordt, A., and Lund, A. (2000). "Sperm whale clicks: Directionality and source level revisited," J. Acoust. Soc. Am. 114, 1143-1154.

Møhl, B., Wahlberg, M., Madsen, P. T., Heerfordt, A., and Lund, A. (2003). "The monopulsed nature of sperm whale clicks," J. Acoust. Soc. Am. 114, $1143-1154$.

Mouy, X., Hannay, D., Zykov, M., Martin, B. (2011). "Tracking of Pacific Walruses in the Chukchi Sea using a single hydrophone," J. Acoust. Soc. Am. 131(2), 1349-1358.
Nosal, E. M., and Frazer, L. N. (2006). "Track of a sperm whale from delays between direct and surface-reflected clicks," Appl. Acoust. 67, $1187-1201$.

Nosal, E.M, and Frazer, LN (2007). "Sperm whale three-dimensional track, swim orientation, beam patter, and click levels observed on bottommounted hydrophones," J. Acoust. Soc. Am. 122(4), 1969-1978.

Oleson, E. M. Calambokidis, J., Burgess, W. C., McDonald, M. A., LeDuc, C. A., and Hildebrand, J. A. (2007). "Behavioral context of call production by eastern North Pacific blue whales," Mar. Ecol. Prog. Ser. 330, 269-284.

Porter, M., and Bucker, H. (1987). "Gaussian beam tracing for computing ocean acoustic fields," J. Acoust. Soc. Am. 82, 1349-1359.

Sigler, M., Lunsford, C. R., Straley, J., and Liddle, J. (2008). "Sperm whale depredation of sablefish longline gear in the northeast Pacific," Mar. Mamm. Sci. 24(1), 16-27.

Thode, A. (2004). "Tracking sperm whale (Physeter macrocephalus) dive profiles using a towed passive acoustic array," J. Acoust. Soc. Am. 116(1), 245-253.

Thode, A., Mellinger, D. K., Stienessen, S., Martinez, A., and Mullin, K. (2002). "Depth-dependent features of diving sperm whales (Physeter macrocephalus) in the Gulf of Mexico," J. Acoust. Soc. Am. 116, 245-253.

Thode, A., Straley, J. M., Tiemann, C. O., Folkert, K., and O'Connell, V. (2007). "Observations of potential acoustic cues that attract sperm whales to longline fishing in the Gulf of Alaska," J. Acoust. Soc. Am. 122(2), 1265-1277.

Thorp, W. H. (1967). "Analytic description of the low-frequency attenuation coefficient,” J. Acoust. Soc. Am. 42(1), 270.

Tiemann, C. O., Porter, M. B., and Frazer, L. N. (2004). "Localization of marine mammals near Hawaii using an acoustic propagation model," J. Acoust. Soc. Am. 115(6), 2834-2843.

Tiemann, C. O., Thode, A., Straley, J., Folkert, K., and O'Connell, V. (2006). "Three-dimensional localization of sperm whales using a single hydrophone," J. Acoust. Soc. Am. 120(4), 2355-2365.

Urick, R. J. (1983). Principles of Underwater Sound, 3rd ed. (McGraw-Hill, New York), 444 pp.

Wenz, G. M. (1962). "Acoustic ambient noise in the ocean: Spectra and sources," J. Acoust. Soc. Am. 34, 1936-1956.

Whitehead, H. (2003). Sperm Whales: Social Evolution in the Ocean (University of Chicago Press, Chicago), $431 \mathrm{pp.}$

Whitehead, H., and Weilgart, L. (1991). "Patterns of visually observable behaviour and vocalizations in groups of female sperm whales," Behaviour 118, 275-296.

Whitney, W. (1968). "Observations of sperm whale sounds from great depths," Marine Physical Laboratory, Scripps Institution of Oceanography Report No. MPL-U 11/68.

Zimmer, W. M. X., Madsen, P. T., Teloni, V., Johnson, M. P., and Tyack, P. L. (2005). "Off-axis effects on the multi-pulse structure of sperm whale usual clicks with implications for the sound production," J. Acoust. Soc. Am. 118, 3337-3345. 